\title{
Estradiol Shapes Auditory Processing in the Adult Brain by Regulating Inhibitory Transmission and Plasticity- Associated Gene Expression
}

\author{
Liisa A. Tremere, Jin Kwon Jeong, and Raphael Pinaud \\ Department of Brain and Cognitive Sciences, University of Rochester, Rochester, New York 14627
}

Estradiol impacts a wide variety of brain processes, including sex differentiation, mood, and learning. Here we show that estradiol regulates auditory processing of acoustic signals in the vertebrate brain, more specifically in the caudomedial nidopallium (NCM), the songbird analog of the mammalian auditory association cortex. Multielectrode recordings coupled with local pharmacological manipulations in awake animals reveal that both exogenous and locally generated estradiol increase auditory-evoked activity in NCM. This enhancement in neuronal responses is mediated by suppression of local inhibitory transmission. Surprisingly, we also found that estradiol is both necessary and sufficient for the induction of multiple mitogen-activated protein kinase (MAPK)-dependent genes thought to be required for synaptic plasticity and memorization of birdsong. Specifically, we show that local blockade of estrogen receptors or aromatase activity in awake birds decrease song-induced MAPK-dependent gene expression. Infusions of estradiol in acoustically isolated birds induce transcriptional activation of these genes to levels comparable with song-stimulated animals. Our results reveal acute and rapid nongenomic functions for estradiol in central auditory physiology and suggest that such roles may be ubiquitously expressed across sensory systems.

\section{Introduction}

The hormone $17 \beta$-estradiol (E2) plays a central role in numerous physiological functions, including the brain's regulation of reproductive behavior, mood, and cognitive processes, such as learning and memory formation (Fillit et al., 1986; McEwen, 2002; Ostlund et al., 2003; Craft et al., 2004; McCarthy, 2008).

Recent evidence suggests that E2 may also impact sensory processing, especially in auditory circuits. In humans, hearing thresholds and auditory event-related potentials correlate with the E2 plasma levels during the menstrual cycle (Davis and Ahroon, 1982; Walpurger et al., 2004). Auditory processing, as assessed by auditory brainstem responses (ABRs), is more efficient in females relative to males (Jerger and Hall, 1980). Furthermore, women with Turner's syndrome, who are deficient in E2, exhibit hearing disorders and lower auditory processing efficiency (Hultcrantz et al., 1994; Hultcrantz and Sylvén, 1997; Güngör et al., 2000). These findings are consistent with results obtained in ro-

\footnotetext{
Received Feb. 15, 2009; revised March 29, 2009; accepted April 5, 2009.

This work was supported by start-up funds from the University of Rochester (R.P.). We are greatly indebted to Dr. Greg DeAngelis for help with Matlab programming. We also thank Drs. L. Carney and M. Zilany for help with noise transformation Matlab codes, Drs. G. DeAngelis, J. Ison, P. Allen, C. Stengel, and L. Carney for invaluable discussions, and Drs. J. Ison, W. Taylor, and A. Majewska for allowing us to use equipment in their laboratories. Dr. C. Mello provided us with the zenk and arc clones and Dr. E. Jarvis with the c-fos clone. S. Hussain provided help with data analysis and A. Varghese with surgeries. Finally, we thank both anonymous reviewers for the highly constructive feedback on our work. R.P. conceived and designed the experiments. R.P., L.A.T., and J.K.J. performed the experiments. L.A.T., J.K.J., and R.P. analyzed the data. L.A.T. and R.P. contributed reagents/materials/analysis tools. R.P. wrote the paper.

Correspondence should be addressed to Dr. Raphael Pinaud, Department of Brain and Cognitive Sciences, 117 Meliora Hall, River Campus, University of Rochester, Rochester, NY 14627. E-mail: pinaud@bcs.rochester.edu. D0I:10.1523/JNEUROSCI.0774-09.2009

Copyright $\odot 2009$ Society for Neuroscience $\quad 0270-6474 / 09 / 295949-15 \$ 15.00 / 0$
}

dents and monkeys, in which ovariectomy alters ABRs (Coleman et al., 1994; Golub et al., 2004); after E2 replacement, however, normal ABRs are reinstated (Coleman et al., 1994). Finally, E2 treatment of nonreproductive female midshipman fish tunes behaviorally relevant auditory processing (Sisneros et al., 2004). The mechanisms underlying such effects, however, are largely unknown, as are brain sites in which potential interactions between sensory and endocrine systems occur.

Songbirds provide an exceptional model for studying the effects of E2 in auditory processing because key social behaviors rely on the bird's ability to perceive and discriminate songs based on their acoustic structure (Gentner, 2004; Nowicki and Searcy, 2004), and socially relevant auditory experience increases E2 levels in the auditory forebrain (Remage-Healey et al., 2008). The caudomedial nidopallium (NCM), a forebrain area thought to be analogous to the mammalian auditory association cortex (Vates et al., 1996; Mello et al., 2004; Bolhuis and Gahr, 2006; Pinaud and Terleph, 2008), contains neurons that are selective to speciesspecific songs (Mello et al., 1992; Chew et al., 1996; Stripling et al., 2001). NCM neurons also undergo stimulus-specific adaptation of neurophysiological and genomic responses; such changes are long lasting and may support auditory discrimination and song recognition memories (Chew et al., 1995; Mello et al., 1995). NCM is also a site of overlap between the auditory and neuroendocrine systems. A large population of NCM neurons expresses aromatase, an enzyme that converts circulating androgens into estrogens (Saldanha et al., 2000; Balthazart et al., 2003). Furthermore, NCM expresses both types of estrogen receptors (ERs) (Balthazart et al., 1992; Bernard et al., 1999; Metzdorf et al., 1999). Thus, local estrogen levels may impact central auditory 
processing, a view supported by recent findings indicating that social interactions increase E2 levels in NCM (Remage-Healey et al., 2008).

Here we investigated whether E2 may impact auditory processing in NCM. We show that E2 enhances hearing-evoked responses by suppressing local inhibitory neurotransmission. E2 is also necessary and sufficient for the expression of mitogenactivated protein kinase (MAPK)-dependent genes putatively involved in auditory plasticity and song memorization. In summary, we demonstrate that E2 rapidly influences auditory processing in a central auditory circuit, through rapid changes in neuronal excitability and modulation of plasticity-associated gene expression.

\section{Materials and Methods}

\section{Extracellular recordings in awake restrained animals}

A total of 94 adult zebra finches were collectively used (see each section below). Importantly, no sex differences were detected in any of the parameters analyzed for each of the experiments described in the present work. Thus, data obtained in male and females were combined. For electrophysiology experiments, we used 54 adult zebra finches $(n=29$ males and 25 females) that were either obtained from a commercial supplier (Magnolia Bird Farm) or raised in our aviary at the University of Rochester. All procedures described below were approved by the University Committee on Animal Resources of the University of Rochester. For neurophysiological recordings in awake, restrained birds, we used methodologies that we have described previously in detail (Pinaud et al., 2008c). Briefly, animals were anesthetized with Equithesin (combination of chloral hydrate at $200 \mathrm{mg} / \mathrm{kg}$ and sodium pentobarbital at $50 \mathrm{mg} / \mathrm{kg}$, i.m.) and placed on a stereotaxic apparatus, in which a window was made on the skull, over NCM and the bifurcation of the sagittal sinus, by removal of the outer bone layer. A metal head post was fixed over the skull, and a recording chamber was formed around the opened round window with dental cement (OrthoJet; Lang Dental Manufacturing). After a recovery period of a minimum of $2 \mathrm{~d}$, awake animals were immobilized in a plastic body tube and, through the head post, fixed to a stereotaxic device that was placed inside a walk-in acoustically isolated sound booth (IAC). While restrained, the remaining layer of bone was removed from the opened window. A multielectrode array consisting of eight tungsten microelectrodes (5-8 $\mathrm{M} \Omega$ ) allowed for the simultaneous and bilateral recording of auditory-evoked responses in the NCM of fully awake zebra finches ( $n=4$ electrodes per hemisphere). Two independent glass pipettes (tip inner diameter of $\sim 20 \mu \mathrm{m}$; Drummond Scientific) with solutions of interest (see below) were lowered in each hemisphere separately, to coordinates adjacent to the microelectrodes. Whitenoise bursts were used to locate responsive sites. Neurophysiological signals were collected in continuous streams with a sampling rate of 30.3 $\mathrm{kHz}$, amplified, filtered above $5 \mathrm{kHz}$ and below $500 \mathrm{~Hz}$, and digitized along with the auditory stimuli using a Neuralynx Cheetah 32 system. All electrophysiological activity consisted of either multiunit responses from a small number of units (three to six) recorded at the tip of each electrode or single units when available. Single units were discriminated by waveform properties (Spike Extraction; Neuralynx), and unit isolation was confirmed by the presence of refractory periods in the interspike interval histograms (see below).

After presentation of a "predrug" stimulation set (see below), the glass pipettes were lowered to the same depth of the electrodes. Vehicle [dimethylsulfoxide (DMSO)] was injected in one hemisphere, whereas the contralateral hemisphere received injections of E2 (Sigma) at either 0.5 or $2 \mathrm{mg} / \mathrm{ml}$, tamoxifen (TMX) (Tocris Cookson) at either 100 or $200 \mu \mathrm{M}$ in DMSO, or 1,4,6-androstatrien-3,17-dione (ATD) (Steraloids) at either $100 \mu \mathrm{M}$ or $1 \mathrm{~mm}$ in DMSO. All injections were performed with calibrated hydraulic Narishige microinjectors. Injections consisted of an initial loading dose $(100 \mathrm{nl})$, followed by maintenance doses of $10 \mathrm{nl}$ every 5-10 min for the remainder of the auditory stimulation session. During the pharmacological manipulation sessions, animals were again subjected to the stimulation set ("drug" condition; see below). In previous experiments, we diluted E2 in sesame oil (and used oil-only injec- tions as controls), but the results obtained with this approach were not significantly different from those obtained with DMSO as a vehicle and, therefore, these datasets were combined. Song stimulation was initiated 5 min after injections of E2 or TMX and $30 \mathrm{~min}$ after injections of ATD. We also measured drug diffusion from our pipettes. Importantly, we found that a single $100 \mathrm{nl}$ injection of vehicle in NCM at our coordinates covered an average radius of $\sim 250 \mu \mathrm{m}$. These parameters, calculated by adding a small volume of Alexa- 488 dye to the vehicle solution in selected animals (not quantified in this study), indicate that our volumes provide relatively broad coverage (including maintenance doses) while restricting its diffusion to NCM. Given that NCM is a large area $(>1.2 \mathrm{~mm})$, our infusions did not likely diffuse away from NCM, even if misplaced by a few hundred micrometers. This assessment, combined with electrode placement confirmation (see below), ensured that drug diffusion was restricted to NCM.

\section{Stimuli}

Auditory stimuli consisted of songs and a series of nonsong stimuli that gradually departed in structure from the conspecific song stimuli used. We next detail each stimulus class and, when necessary, how they were created. (1) Four conspecific song motifs (CON) had stimulus durations of $0.70,0.67,0.72$, and 0.73 s. (2) Reverse songs (REV) consisted of each of the four conspecific songs listed above, played backwards. This manipulation preserves the spectral, but alters the temporal, components of each song. Stimulus durations remain unchanged. (3) Phaserandomized songs (PRS) consisted of a randomization of the phase of the different frequency components of each conspecific song used. This manipulation preserves the long-term spectrum of the signal but discards the temporal information. To phase randomize each of the four songs, the sampled values contained in individual ${ }^{*}$.wav files (each song) were fast Fourier transformed (FFT). The magnitudes at different frequencies are preserved after this manipulation. Subsequently, random phases in the range of $0-2 \pi$ were generated for all frequencies. Magnitudes computed using FFT were combined with the random phases to generate complex numbers, and the inverse FFT of these numbers was computed. This time-domain signal was then written into $a^{*}$.wav file. This manipulation yielded four files that derived from each of the four conspecific songs. Stimulus durations were, therefore, unchanged. All manipulations necessary for generating PRS were performed in custom-made Matlab routines. (4) Frequency-constrained noise (FCN) consisted of a band-limited noise within the full range of zebra finch song elements $(0.1-7 \mathrm{kHz})$. We generated a single FCN file of $700 \mathrm{~ms}$ in duration. This stimulus encompassed 10-ms-long raised cosine on and off ramps that were applied to the beginning and at the end of the noise, respectively. The noise envelope consisted of the on and off ramps and a constant function of 1 for the central $680 \mathrm{~ms}$. Gaussian random numbers were generated for the $700 \mathrm{~ms}$ duration, which corresponded to $30,303 * 0.7$ sample points, where $30,303 \mathrm{~Hz}$ was the sampling rate. This manipulation generated broadband noise. To limit the noise in the spectral range of zebra finch songs, we computed the FFT of the noise. The spectrum of the noise was restricted between 0.1 and $7 \mathrm{kHz}$, and the inverse FFT of this band-limited noise was computed to bring the stimulus into the time domain. This band-limited noise was multiplied by the envelope computed previously and written into a ${ }^{\star}$.wav file. The manipulations associated with the generation of FCN were conducted in custom-made Matlab routines. (5) Frequency stack (FS) consisted of a single stimulus encompassing the simultaneous presentation of six pure tones in the range of most zebra finch song elements ( $1-6 \mathrm{kHz}$ in $1 \mathrm{kHz}$ increments). Sine wave pure tones for each frequency were generated and stacked using Audacity software and written as a ${ }^{\star}$.wav file. Stimulus duration was $700 \mathrm{~ms}$.

All stimuli were played at $70 \mathrm{~dB}$ sound pressure level amplitude through a speaker, in pseudorandom order, via the control of a customwritten multi-trial sequence program (Neuralynx). Each stimulus was played 25 times, followed by 25 presentations of the same stimuli before the injection of solutions of interest in each hemisphere, and then repeated 25 additional times during drug treatment. 


\section{Analysis of neurophysiological responses}

Electrophysiological responses were obtained at each recording site to enable valid comparisons between conditions (before vs during drug treatment). Neuronal responses were measured as mean firing rates (NeuroExplorer; Nex Technologies). All data associated with mean firing rates (see Fig. $2 A, C, E$ ) are based on either isolated single units $(37 \%)$ or units that were sorted from multiunit recordings (three to six units; $63 \%$ of the analyzed neurons). In separate analyses, we quantified the rectified response amplitude of our neural data by pooling single unit and multiunit neuronal activity recorded in continuous mode (see Fig. $2 B, D, F$ ). This was accomplished by quantifying the difference between the mean absolute [the root-mean-squared (RMS)] value obtained for each electrode during a response window (from stimulus onset to stimulus offset plus $100 \mathrm{~ms}$ ) and the mean absolute value during a control window (500 $\mathrm{ms}$ before stimulus onset) (Pinaud et al., 2008c). To compute these values either for control or stimulus windows, each digitized value is squared, the mean of these squares over the response interval is computed, and the square root of that mean is obtained. We used these RMS values to compute drug-induced changes in response amplitudes, in the form of a post/pre ratio. To this end, subtracted RMS values (stimulus window minus control window) for each electrode were obtained for each of the 25 trials of the experimental (postdrug) session. These values were averaged across the 25 trials to obtain a single postdrug RMS value per electrode. We next obtained predrug subtracted RMS values for each of the 25 trials of the predrug session for each electrode. These predrug RMS values were averaged across the 25 trials to obtain a single predrug RMS value per electrode. The ratio of the response amplitudes was obtained by dividing the averaged postdrug RMS by the averaged predrug RMS for each electrode. These ratios were then averaged across recording sites in each hemisphere. This method provides a means of rectifying either single unit or multiunit neural activity for averaging across trials and calculating its average power (hence, we occasionally refer to results obtained with this method as the "rectified response amplitude" in the present work). The RMS approach is also highly useful to measure variability induced by drug application at each recording site, in the form of postdrug/predrug response amplitude ratios, as described above (a ratio of 1 indicates no drug-induced changes in response amplitude, whereas ratios $<1$ or $>1$ indicate decreases or increases in response amplitude, respectively), as detailed previously (Pinaud et al., 2008c).

One important distinction between the RMS method and standard measurements of discharge rate is that the former takes into consideration spontaneous and baseline activity in the calculation of final amplitude values. Thus, along with discharge rate measurements, the RMS method provides a complementary approach for assessing drug-induced changes in neuronal physiology, thereby providing a more comprehensive description of the physiological changes in NCM responses (Chew et al., 1995, 1996; Pinaud et al., 2008c).

For stimuli classes that contained more than one stimulus (i.e., CON, REV, and PRS, which consisted of four stimuli each), changes in discharge rates and RMS values were averaged across stimuli.

With the exception of firing rates, all data were analyzed with customwritten Matlab routines. Spontaneous activity was measured in the $5 \mathrm{~min}$ interval between drug infusion and stimulation onset, as well as within the interstimulus interval. In initial experiments, either E2 or TMX were injected unilaterally, without vehicle injections in the contralateral hemisphere. The results obtained with this approach were not significantly different from those obtained with our double injections (vehicle in one hemisphere and E2, TMX, or ATD) in the other hemisphere. However, we report here just the data associated with animals injected bilaterally.

Neurophysiological responses were analyzed with parametric statistics, as appropriate; however, nonparametric tests were used when normality assumptions were violated. Factorial ANOVAs included recordings from the same electrode before versus during drug (vehicle, E2, TMX, or ATD) as a repeated measure and used data from each recording site as a sample. To avoid pseudo-replication effects, the degrees of freedom used when computing the probability for each $F$ value were reduced to the number of stimuli and/or birds, as appropriate. Statistical significance thresholds were set at $p<0.05$.

\section{Confirmation of electrode placement}

At the end of the recording session, electrolytic lesions (15 $\mu \mathrm{A}$ of current for $10 \mathrm{~s}$ ) were performed in both hemispheres of all birds used in our studies. Animals were anesthetized with an overdose of Equithesin and perfused transcardially with $20 \mathrm{ml}$ of $0.1 \mathrm{M}$ phosphate buffer (PB) and 60 $\mathrm{ml}$ of a cold $4 \%$ solution of paraformaldehyde in $0.1 \mathrm{M} \mathrm{PB}$. Brains were then cryoprotected, frozen, cut at $30 \mu \mathrm{m}$ on a cryostat, and stained for cresyl violet histochemistry (Pinaud et al., 2008c).

\section{Whole-cell patch-clamp electrophysiology}

We performed whole-cell patch-clamp recordings in a slice preparation containing NCM that we developed (Pinaud et al., 2004, 2008c). A total of 20 adult zebra finches ( $n=10$ males and 10 females) were used for these experiments. Brains were obtained through decapitation and were rapidly placed in artificial CSF (aCSF) modified for slicing, which consisted of the following (in $\mathrm{mM}$ ): $87 \mathrm{NaCl}, 25 \mathrm{NaHCO}_{3}, 2.5 \mathrm{KCl}, 1.25$ $\mathrm{NaH}_{2} \mathrm{PO}_{4}, 0.5 \mathrm{CaCl}_{2}, 7 \mathrm{MgCl}_{2}, 25$ glucose, 75 sucrose, 0.4 ascorbic acid, 2 sodium pyruvate, 3 myo-inositol, and $354 \mathrm{mOsm} / \mathrm{kg} \mathrm{H}_{2} \mathrm{O}$, pH 7.4 when bubbled with carbogen $95 \% \mathrm{O}_{2} / \% \mathrm{CO}_{2}$. Parasagittal sections (250 $\mu \mathrm{m}$ thick; three sections starting at the midline) spanning NCM were rapidly obtained on a vibratome. For the recording session, sections were placed in a chamber mounted on an upright microscope and constantly perfused with regular aCSF (in mM): $125 \mathrm{NaCl}, 2.5 \mathrm{KCl}, 25 \mathrm{NaHCO}_{3}$, $1.25 \mathrm{NaH}_{2} \mathrm{PO}_{4}, 25$ glucose, $2 \mathrm{CaCl}_{2}, 1 \mathrm{MgCl}_{2}, 0.4$ ascorbic acid, 2 sodium pyruvate, 3 myo-inositol, and $310 \mathrm{mOsm} / \mathrm{kg} \mathrm{H}_{2} \mathrm{O}$, pH 7.4 when bubbled with $95 \% \mathrm{CO}_{2} / 5 \% \mathrm{O}_{2}$. Cells were visualized with infrared differential interference contrast and patched with borosilicate glass pipettes (Sutter Instruments). The internal solution of recording glass pipettes consisted of the following (in mM): $140 \mathrm{CsCl}, 5$ EGTA, 10 HEPES, 4 ATP-Mg, and 20 phosphocreatine- $\mathrm{Na}, \mathrm{pH} 7.3$ with $\mathrm{CsOH}$. Miniature postsynaptic currents (mPSCs) were obtained as described in detail previously (Pinaud et al., 2008c). Briefly, neurons were recorded in whole-cell configuration with a HEKA patch-clamp amplifier. Cells were held at $-70 \mathrm{mV}$ for all experiments. Resistance of the pipettes in the bath was in the 7-13 M $\Omega$ range and compensated series resistance up to $20 \mathrm{M} \Omega$. To pharmacologically isolate neurotransmission performed by excitatory or inhibitory mechanisms, we used bicuculline (BIC) $(20 \mu \mathrm{M})$, a competitive $\mathrm{GABA}_{\mathrm{A}}$ antagonist, and DNQX $(20 \mu \mathrm{M})$, an AMPA/kainate antagonist. The $17 \beta-$ estradiol, BIC, and DNQX were obtained from Sigma, TMX was purchased from Tocris Cookson, and ATD was from Steraloids. All compounds were diluted in DMSO, and their chosen concentrations were well within the standard range used in neuronal preparations (E2 at 50 $\mathrm{nM}$, TMX at $2 \mu \mathrm{M}$, and ATD at $20 \mu \mathrm{M}$ ) (Wade et al., 1994; ChesnoyMarchais, 2003, 2005; Duncan, 2005; Nishimura et al., 2008; Romanò et al., 2008). For experiments involving blockade of aromatase activity, adjacent slices were either preincubated in aCSF containing ATD (experimental) or aCSF alone (control) for $30 \mathrm{~min}$ before the recording session. Action potentials were blocked by application of tetrodotoxin citrate (Tocris Cookson) (Pinaud et al., 2008c). Properties of mPSCs, including time-to-peak, decay time, area, and threshold, were analyzed using the mini analysis graphical user interface in Igor Pro (Wavemetrics). Confirmation of minis was performed manually by the investigator (Pinaud et al., 2008c). mPSC mean frequency and amplitudes were considered to follow a normal distribution after passing a Kolmogorov-Smirnoff normality test. Therefore, data were analyzed using parametric statistics, as appropriate, with significance set at $p<0.05$.

\section{Pharmacological manipulations in awake, restrained birds}

All birds $(n=20)$ used for bilateral intracerebral injection experiments were fitted with head posts and an access skull chamber, as described above for electrophysiological experiments and detailed previously (Velho et al., 2005; Pinaud et al., 2008c). Birds were allowed to recover for a minimum of $48 \mathrm{~h}$ before experimentation.

Acclimation sessions. After the recovery period, animals were subjected to several acclimation sessions that were aimed at minimizing potential procedural effects on the expression of the immediate early genes (IEGs) studied. Acclimation sessions were initiated $24 \mathrm{~h}$ before the injection sessions and were performed in the walk-in sound-isolation booth. Each session consisted of gently placing animals in the body restraint tube and 
fixing their head posts to the stereotaxic device. Animals remained restrained for a total of $15 \mathrm{~min}$ (or $30 \mathrm{~min}$ for birds subjected to ATD injections; see below) in the presence of the investigator. Subsequently, animals were removed from the stereotaxic apparatus and individually placed in acoustic isolation boxes (which were located inside the walk-in sound-isolation booth). Five acclimation sessions (one every $1.5 \mathrm{~h}$ ) were conducted before the injection day, and a last session was performed on the morning of the experiment. When not undergoing acclimation sessions, birds were maintained at all times inside the sound isolation boxes.

Intracerebral microinjections of E2 or TMX. At $1.5 \mathrm{~h}$ after the last acclimation session, birds were once again restrained and affixed to the stereotaxic device. The inner layer of bone within the injection window was then removed, and two independent glass pipettes were lowered into NCM. Relative to the bifurcation of the sagittal sinus, the NCM coordinates used in our experiment were as follows: anteroposterior, $0.5 \mathrm{~mm}$; mediolateral, $0.5 \mathrm{~mm}$; dorsoventral, $1.4 \mathrm{~mm}$. One hemisphere always received vehicle (DMSO), whereas the other hemisphere received either E2 $(2 \mathrm{mg} / \mathrm{ml})$ or TMX (100 $\mu \mathrm{M})$. Therefore, each animal served as its own control, especially given that no interhemispheric connectivity exists in NCM or its afferent and efferent projection sites (Vates et al., 1996; Mello et al., 1998) (for injection placements, see supplemental Fig. 1, available at www.jneurosci.org as supplemental material). One-hundred nanoliters of solution was injected in each NCM via Narishige hydraulic microinjectors, and glass pipettes were left in place after injection for a total of $2 \mathrm{~min}$ to avoid reflux of solution through the pipette track. Glass pipettes were then retracted, and animals were returned to the acoustic isolation boxes in which they were exposed to one of two conditions. (1) The stimulated group consisted of 15 min auditory stimulation plus 15 min silence ( 30 min after stimulation onset coincides with peak song-induced IEG mRNA accumulation). Stimulation consisted of playbacks of a medley of four conspecific songs (one song every $30 \mathrm{~s}$ ). (2) The control group consisted of $30 \mathrm{~min}$ of silence (see Figs. $4 \mathrm{~A}, 6 \mathrm{~A}$ ). After fulfilling group criteria, animals were rapidly removed from isolation boxes and decapitated, and brains were rapidly extracted, frozen, and cut parasagittally on a cryostat (12 $\mu \mathrm{m}$ thickness), for gene expression studies.

Intracerebral microinjections of ATD. Birds included in this experiment received unilateral injections of vehicle (DMSO) and contralateral infusions of a solution containing ATD $(100 \mu \mathrm{M})$. ATD at this concentration has been shown previously to specifically and effectively suppress aromatase activity in the zebra finch brain (Wade et al., 1994). All manipulations in birds assigned to ATD injections were identical to E2- and TMX-injected birds, as detailed above, with the following exceptions. First, the acclimation sessions of animals subjected to ATD injections lasted $30 \mathrm{~min}$ (every $1.5 \mathrm{~h}$ ), instead of $15 \mathrm{~min}$. Second, the injection of ATD was divided into two parts; $50 \mathrm{nl}$ were initially injected. Animals were then kept restrained for $30 \mathrm{~min}$ with the injection pipette in place, at which point the remaining $50 \mathrm{nl}$ of the ATD solution were infused. After the second infusion, pipettes were left in place for $2 \mathrm{~min}$, and animals were returned to the individual acoustic isolation boxes and subjected to either silence or song playbacks, as detailed above. We opted to inject ATD 30 min before the stimulation onset, because it has been shown previously that (1) aromatase activity is effectively suppressed $\sim 15$ min after ATD treatment, at our chosen concentration, in zebra finch brain (Wade et al., 1994) and (2) local E2 levels in NCM are markedly decreased within $30 \mathrm{~min}$ after blockade of aromatase activity (Remage-Healey et al., 2008). Finally, ATD infusions were divided into two stages to ensure that sustained drug levels persisted until the song stimulation period.

\section{Fluorescence in situ hybridization}

We used a fluorescence in situ hybridization (FISH) protocol that we developed and described in detail previously (Pinaud et al., 2004, 2008b). Briefly, Qiagen miniprep kit was used to purify plasmids containing zebra finch homologs of the zenk, c-fos, and arc genes from bacteria. The zenk probes were derived from the cloned canary homolog (Mello et al., 1992), and the arc clone was originally obtained through PCR cloning (Velho et al., 2005). The c-fos clone was derived from the Songbird Transcriptome initiative (Duke University, Durham, NC; http://www. songbirdtranscriptome.net/). Plasmids were either linearized by digestion with appropriate restriction enzymes (zenk and $a r c$ ) or amplified by
PCR (c-fos). The cDNAs were purified and used as templates for the generation of digoxigenin (DIG)-labeled antisense and sense strand riboprobes, which were purified in G-50 columns and evaluated for yield in a spectrophotometer (Pinaud et al., 2004, 2008b). Sections were sequentially (1) incubated in a $4 \%$ paraformaldehyde solution in $0.1 \mathrm{~m}$ PBS for $5 \mathrm{~min}$, (2) rinsed in $0.1 \mathrm{M}$ PBS, (3) dehydrated in a standard series of alcohols, (4) air dried, (5) incubated for $10 \mathrm{~min}$ at room temperature (RT) in an acetylation solution ( $1.35 \%$ triethanolamine and $0.25 \%$ acetic anhydride in water), (6) rinsed three times with $2 \times$ saline-sodium phosphate-EDTA (SSPE), and (7) dehydrated in the alcohol series and air dried. Each section was then incubated in $16 \mu \mathrm{l}$ of a hybridization solution that consisted of $50 \%$ formamide, $2 \times$ SSPE, $2 \mu \mathrm{g} / \mu \mathrm{l} \mathrm{tRNA}, 1$ $\mu \mathrm{g} / \mu \mathrm{l} \mathrm{BSA}, 1 \mu \mathrm{g} / \mu \mathrm{l}$ poly(A) in DEPC-treated water, and $1 \mathrm{ng} / \mu \mathrm{l}$ of our DIG-labeled probe of interest (either sense or antisense). Slides were then coverslipped, sealed by immersion in mineral oil bath, and incubated overnight at $62^{\circ} \mathrm{C}$. The following day, sections were then rinsed in chloroform, decoverslipped in $2 \times$ saline-sodium phosphate-EDTA (SSPE), and sequentially washed in (1) $2 \times$ SSPE for $1 \mathrm{~h}$ at RT, (2) $2 \times$ SSPE containing $50 \%$ formamide for $1.5 \mathrm{~h}$ at $62^{\circ} \mathrm{C}$, and (3) $0.1 \times$ SSPE two times for $30 \mathrm{~min}$ at $62^{\circ} \mathrm{C}$. Sections were then incubated in $0.3 \%$ hydrogen peroxide in TNT buffer $(0.1 \mathrm{M}$ Tris- $\mathrm{HCl}, \mathrm{pH} 7.4,5 \mathrm{M} \mathrm{NaCl}$, and $0.05 \%$ Triton X-100 in DEPC-treated water) for $10 \mathrm{~min}$, washed in TNT buffer (three times for $5 \mathrm{~min}$ ), and incubated for $30 \mathrm{~min}$ in TNB buffer (TNT plus $2 \mathrm{mg} / \mathrm{ml}$ bovine serum albumin). Subsequently, sections were incubated in a solution containing a peroxidase-coupled anti-DIG antibody for $2 \mathrm{~h}$ at RT (1:200 dilution in TNB; Roche Diagnostics), washed in TNT buffer (three times for $5 \mathrm{~min}$ ), and incubated in a solution containing tyramide-linked Alexa-488 in amplification buffer provided by the manufacturer (Invitrogen). Sections were again washed in TNT buffer (three times for $5 \mathrm{~min}$ ), counterstained with Hoechst, washed in TNT (three times for $5 \mathrm{~min}$ ), and coverslipped with Vectashield (Vector Laboratories) for histological analyses. Sense strand riboprobes for all genes studied did not yield detectable signal. In addition, the expression of all three IEGs, as revealed by antisense riboprobe hybridization, were identical to expression patterns described previously (e.g., IEGs were induced by song, and their expression was absent in field L2a; these control data were obtained from separate animals not included in this study) (Mello et al., 1992; Pinaud et al., 2004; Velho et al., 2005).

\section{FISH quantification and figure preparation}

Sections subjected to FISH were examined on an Olympus AX-70 microscope equipped with appropriate filters and a motorized stage, and coupled to a personal computer containing Neurolucida software (MicroBrightField). As detailed above, we determined that a single $100 \mathrm{nl}$ injection of fluorophores diluted in vehicle diffuses an $\sim 250-300 \mu \mathrm{m}$ radius in NCM (data not shown). Thus, our analyses were focused within $300 \mu \mathrm{m}$ of the pipette tip, in which drug concentrations were presumably more stable. Pipette tracks and the approximate tip location were relatively easily identified by Hoechst counterstaining and phase-contrast microscopy. In addition, an adjacent series of cresyl violet-stained sections for each hemisphere of all animals was used to further confirm the location of injection sites (supplemental Fig. 1, available at www.jneurosci.org as supplemental material). We have described previously our quantification method in detail (Pinaud et al., 2004, 2006). Briefly, to estimate the number of IEG-positive neurons per unit area, an investigator blind to treatment counted labeled neurons as profiles within a grid of $100 \times 100 \mu \mathrm{m}$ squares that was superimposed over the target area of FISH-labeled sections. The inclusion criteria consisted of clearly labeled neurons with nuclei that were negative for IEG mRNAs but positive for Hoechst. A minimum of 15 randomly selected, nonoverlapping squares were quantified per hemisphere, for each animal. The values obtained for each square were separately averaged for each hemisphere of individual animals and, subsequently, within groups. Comparisons across groups were performed using a standard ANOVA with a criterion of significance set at $p<0.05$.

Photomicrographs were acquired through a Digital camera (Firewire CCD; Optronics) coupled to the microscope. Adobe Photoshop software was used for the final assembly of figure plates. 
A

B
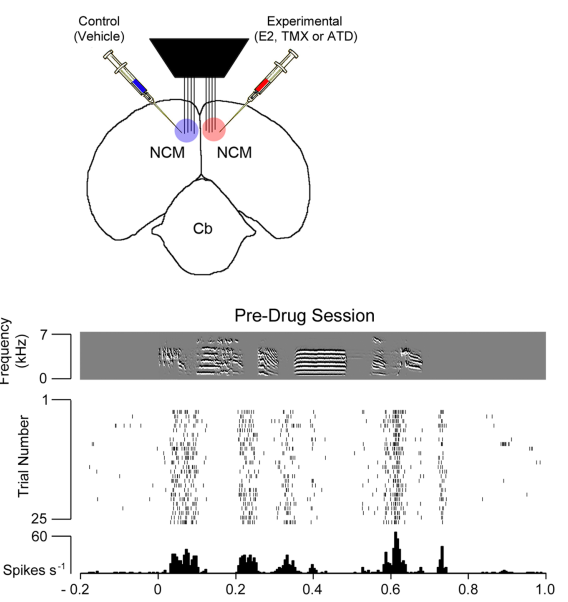

C
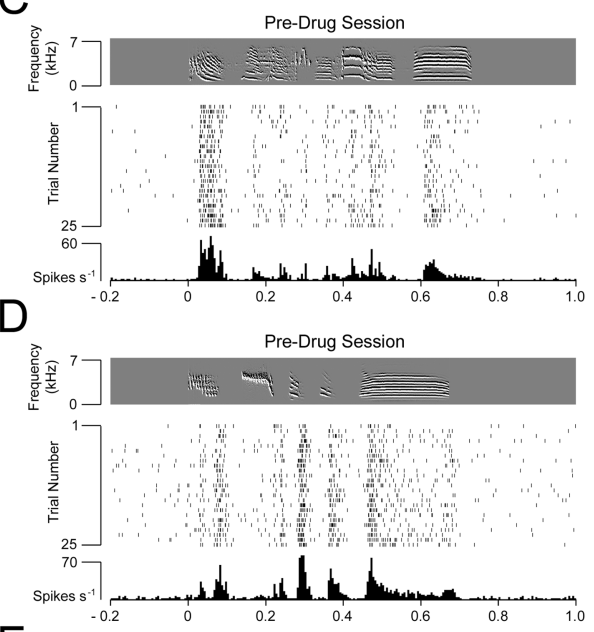

E

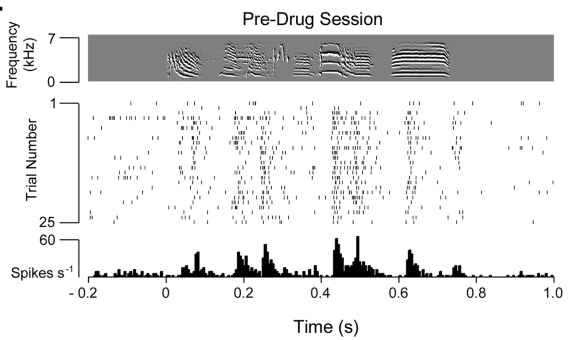

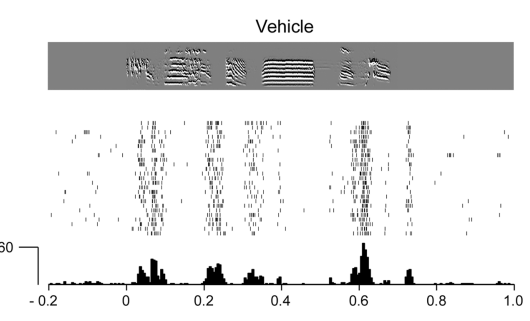

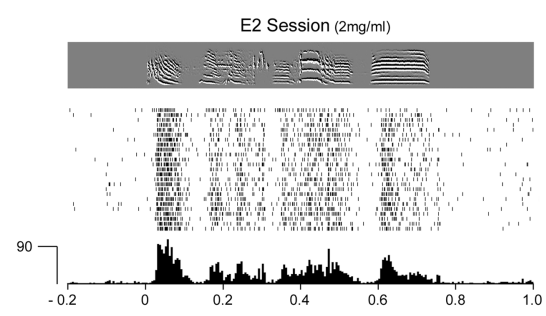

TMX Session (100 $\mu \mathrm{M})$
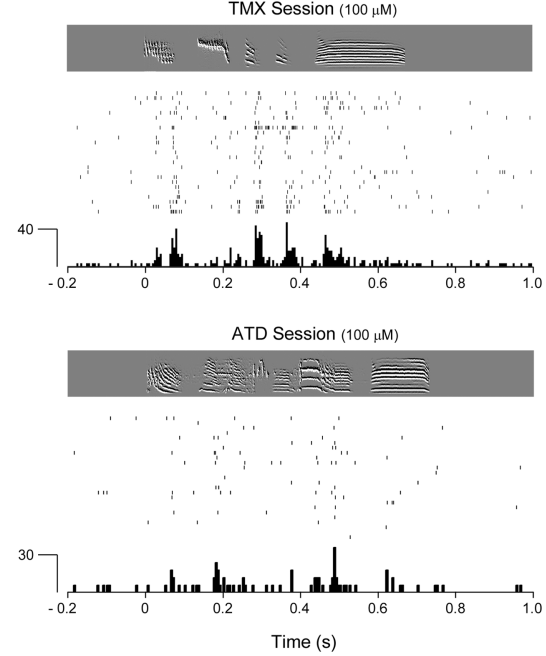

Figure 1. E2 enhances song-evoked spiking activity in NCM neurons. $\boldsymbol{A}$, Schematic representation of recording setup. Animals were fully awake and restrained during the recording sessions, when four electrodes were placed within the NCM of each hemisphere. Glass pipettes were used to stereotaxically deliver vehicle in one hemisphere (control) and E2, TMX, or ATD in the other hemisphere (experimental), in the vicinity of the electrodes. $\boldsymbol{B}$, Profile of the response of a representative neuron to song stimulation before (left) and during (right) local infusion of vehicle. Represented are the spectrograms of the song stimulus (frequency $\times$ time; top row), raster plots for the spiking behavior of the same neuron during each of the 25 renditions of the stimulus (middle row), and corresponding peristimulus time histograms (PSTHs) (bottom row). Note that the spiking behavior was not qualitatively impacted by vehicle infusions, as confirmed by quantitative and statistical analyses (see Results). C, Spike raster plot of a single NCM neuron (middle row), time aligned with the spectrogram of the song stimulus (top row) both before and during application of $2 \mathrm{mg} / \mathrm{ml}$ E2 (left and right, respectively). Local E2 infusion noticeably increased spiking behavior of single NCM neurons, as seen in the raster plots and PSTHs (bottom row). Note the scale differences in the PSTHs. D, Raster plots (middle row) and PSTHs (bottom row) of the song-evoked spiking activity of a representative neuron before (left) and during (right) application of TMX. Song-evoked spiking frequency was clearly reduced after TMX treatment, which was confirmed by quantitative analyses (see Results). $\boldsymbol{E}$, Song-driven spiking activity of a representative NCM neuron before (left) and during (right) ATD treatment. Song spectrograms (top row), spike raster plots (middle row), and PSTHs (bottom row) illustrate a significant suppression of song-induced neural activity, suggesting that locally produced E2 markedly impacts the physiology of NCM neurons.

\section{Results}

E2 modulates song-evoked activity in awake songbirds

As indicated above, NCM neurons express aromatase and ERs, suggesting that this central auditory area is capable of both pro- ducing and being affected by local E2 levels (Balthazart et al., 1992; Bernard et al., 1999; Metzdorf et al., 1999; Saldanha et al., 2000; Fusani et al., 2001; Pinaud et al., 2006) (supplemental Fig. 2, available at www.jneurosci.org as supplemental material). To directly test whether E2 contributes to processing of auditory signals in NCM, we combined bilateral, multielectrode extracellular recordings in awake, restrained zebra finches, with local pharmacological manipulations during playbacks of a randomized series of conspecific songs (see Materials and Methods) (Fig. 1A). We have both developed and previously used this approach to investigate how GABAergic transmission contributes to the physiology of the NCM (Pinaud et al., 2008c). Before drug treatment, NCM neurons responded vigorously to the song playback. This auditory-driven activity could be detected across most electrodes in both hemispheres, and spiking activity typically occurred in-phase with each song syllable (Fig. $1 B$ ).

The median song-evoked firing rate across all stimuli before pharmacological treatment was $39.5 \pm 12$ spikes $/ \mathrm{s}( \pm \mathrm{SE}$ ). Although this rate was not impacted by the infusion of vehicle in one hemisphere during the experimental session $(p=0.14$; $n=30$ birds from two conditions; see below), contralateral application of E2 significantly increased the spike rate of single units in NCM in a dose-dependent manner. Whereas infusion of $0.5 \mathrm{mg} / \mathrm{ml} \mathrm{E} 2$ significantly increased the mean firing rate of NCM neurons from $36.1 \pm 17$ spikes/s in the predrug session to $60.64 \pm 22$ during drug treatment (mean $\pm \mathrm{SE} ; p=0.02 ; n=$ 12 birds), application of $2 \mathrm{mg} / \mathrm{ml}$ increased song-evoked spiking rates from $41.53 \pm 14$ to $101.88 \pm 31$ spikes $/ \mathrm{s}(p<0.001 ; n=18$ birds) (Figs. 1C, 2A). These E2-mediated changes in firing behavior amounted to increases of 67.9 and $145.3 \%$, for 0.5 and 2 $\mathrm{mg} / \mathrm{ml}$ conditions, respectively, relative to preinjection levels (Fig. 2A).

To further quantify the effects of $\mathrm{E} 2$ on song-evoked responses, we calculated a ratio between the response amplitude after and before E2 treatment (a value of 1 indicates no effect; see Materials and Methods). When comparing control and E2 recording sites, we detected a significant difference in this ratio for both 0.5 and 2 $\mathrm{mg} / \mathrm{ml}$ conditions $(p=0.013$ and $p=$ 0.024 , respectively). Although this ratio approximated a value of 1 in control hemispheres, E2-treated hemispheres exhibited average ratios of $1.17 \pm 0.04$ and $1.63 \pm 0.1$ for 0.5 and $2 \mathrm{mg} / \mathrm{ml}$ conditions, respectively (Fig. $2 B$ ). These findings indicate that the amplitude of song-evoked responses of NCM neurons increases $\sim 17.2$ and 
A

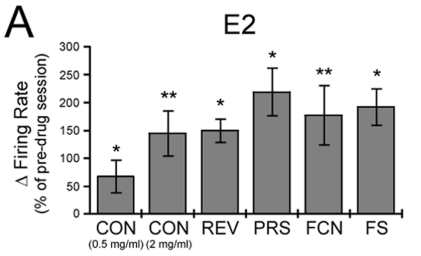

C

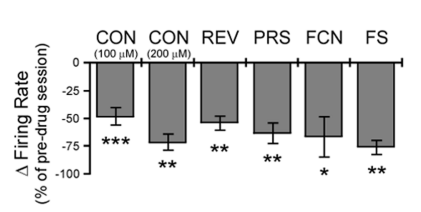

$\mathrm{E}$

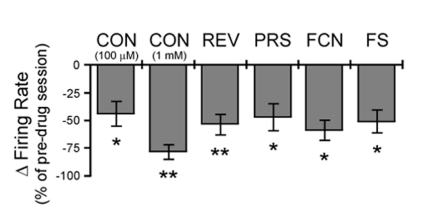

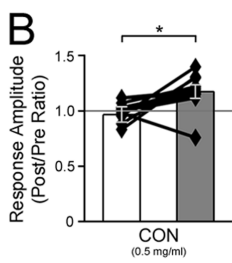
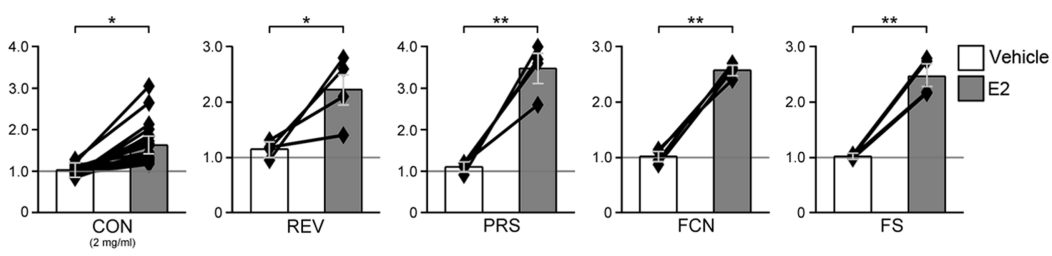

D
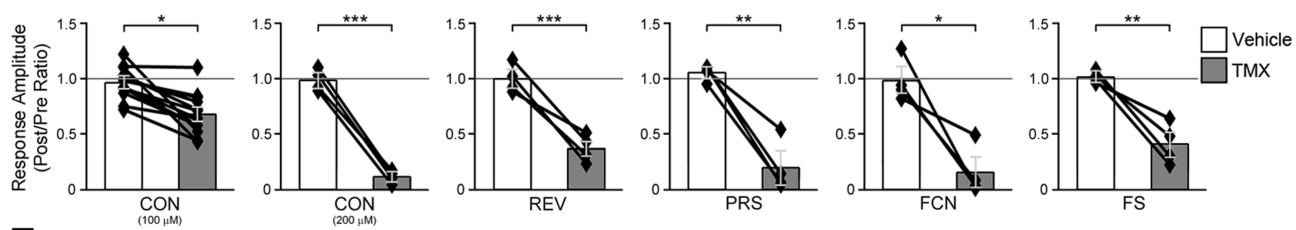

$\mathrm{F}$
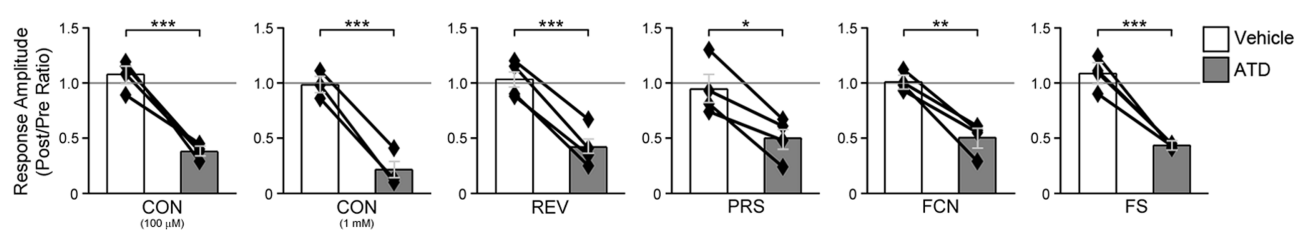

Figure 2. E2 quantitatively increases, and TMX and ATD decrease, neuronal firing rates and rectified response amplitudes of NCM neurons during auditory stimulation. $A$, Bar graphs depicting the E2-induced variation in the mean firing rate of NCM neurons in response to conspecific songs $(0.5$ and $2 \mathrm{mg} / \mathrm{ml})$ or nonsong $(2 \mathrm{mg} / \mathrm{ml})$ auditory stimuli. Nonsong auditory stimuli included REV, PRS, FCN, and FS (for details, see Materials and Methods). Data are expressed as average percentage changes relative to the predrug session. Note that E2 increased neuronal firing rates in a dose-dependent manner, to levels that were significantly higher than the predrug session, and that this effect was not selective for conspecific songs but rather generalized to all auditory stimuli. $B$, Response amplitude for all stimuli were quantified as the difference between the mean absolute (RMS) values during the response period (stimulus duration $+100 \mathrm{~ms}$ ) and the mean absolute values within a prestimulus window $(500 \mathrm{~ms}$ ) (see Materials and Methods). The postdrug (vehicle or E2) value was divided by the predrug value to obtain a ratio (a value of 1 indicates no effect; gray horizontal line). Vertical bars of histograms represent group averages for each condition, and diamonds illustrate the ratios obtained for each individual subject that contributed to that mean; SE is indicated by the light gray error bars. Comparisons are shown for average ratio values between control (vehicle) and experimental (E2-treated) hemispheres. Significant increases in this ratio were observed for all stimuli relative to control levels, indicating increased song-evoked response amplitudes. C, In contrast to the effects observed with E2, TMX treatment significantly decreased mean song-evoked firing rates for all stimuli tested. Shown are the effects of two different TMX concentrations (100 and $200 \mu \mathrm{M}$ ) on conspecific song-evoked discharge rates for NCM neurons and the impact of TMX $(200 \mu \mathrm{M})$ treatment on all nonsong stimuli. Firing rates of vehicle-treated neurons were not significantly changed (condition not depicted in bar graph; see Results). D, Response amplitude values for both song $(100$ and $200 \mu \mathrm{M})$ and nonsong $(200 \mu \mathrm{M})$ auditory stimuli were significantly decreased after TMX treatment relative to vehicle-injected hemispheres. Depicted are comparisons between response amplitude values for each stimulus category, for both control and experimental hemispheres, as assessed by a post/pre ratio (see above; for details, see Materials and Methods). $\boldsymbol{E}$, Spiking activity in NCM neurons driven by both song and nonsong auditory stimuli is markedly suppressed by local infusions of ATD, a specific aromatase inhibitor. The bar graphs indicate that infusions of ATD in NCM significantly suppress song-driven neural activity in a dose-dependent manner (100 $\mu \mathrm{M}$ and $1 \mathrm{mM}$ ). Similarly, discharge rates of NCM neurons that occurred in response to nonsong stimuli were markedly suppressed by ATD treatment $(100 \mu \mathrm{M})$, suggesting that locally produced E2 dramatically impact the physiology of NCM neurons during the processing of auditory information. $\boldsymbol{F}$, Response amplitude ratios for conspecific songs $(100 \mu \mathrm{m}$ and $1 \mathrm{~mm})$ and nonsong $(100 \mu \mathrm{m})$ auditory stimuli were significantly decreased after ATD treatment compared with ratios obtained from control hemispheres. ${ }^{*} p<0.05,{ }^{* *} p<0.001$, and ${ }^{* * *} p<0.0001$.

$63.2 \%$ after 0.5 and $2 \mathrm{mg} / \mathrm{ml} \mathrm{E2} \mathrm{infusions.} \mathrm{Overall,} \mathrm{these} \mathrm{findings}$ suggest that local E2 levels increase NCM neuronal responses during song presentation and, therefore, play a direct role in auditory processing.

We next tested whether blockade of ERs impacts the response profile of NCM neurons during auditory processing of songs. We performed in vivo experiments as detailed above, except that TMX, a selective ER modulator, was infused in place of E2. TMX treatment significantly decreased mean firing rate from $49.75 \pm$ 11.2 to $25.66 \pm 4.5$ spikes/s and from $39.52 \pm 5.7$ to $11.29 \pm 4.8$ spikes/s for 100 and $200 \mu \mathrm{M}$ conditions, respectively $(p<0.0001$ and $p=0.01$, respectively; $n=17$ birds) (Fig. $1 D$ ). This change reflected, on average, 48.4 and $71.4 \%$ decreases in the spiking rate of single units before versus during drug application for 100 and $200 \mu \mathrm{M}$, respectively (Fig. $2 C$ ). These decreases are further evidenced when quantifying post/pre-TMX and control amplitude ratios. Relative to vehicle-infused hemispheres, TMX-treated hemispheres exhibited average ratios of $0.68 \pm 0.05$ and $0.10 \pm$ 0.03 for 100 and $200 \mu \mathrm{M}$ conditions, indicating significant dosedependent decreases of 29.9 and $89.7 \%$ in NCM neuronal response amplitudes from control levels $(p=0.023$ and $p<0.001$ for 100 and $200 \mu \mathrm{M}$, respectively) (Fig. 2D). These data suggest that local modulation of ERs with TMX significantly decreases the responsiveness of NCM neurons to song auditory input.

\section{E2 modulates nonsong auditory responses in awake songbirds}

The in vivo experiments described above show that changes in the local levels of E2 directly impact song-evoked auditory responses in the NCM of awake zebra finches. As indicated previously, NCM exhibits selective responses to conspecific songs relative to heterospecific songs and artificial stimuli, as revealed by electrophysiological methods and activity-regulated gene expression (Mello et al., 1992; Chew et al., 1996; Velho et al., 2005). Based on this selectivity, we next asked whether the effects of E2 in the physiology of NCM are restricted to certain types of auditory stimuli, namely conspecific songs, or also generalize to nonsong auditory stimuli. To address this question, we performed bilateral multielectrode recordings coupled to local pharmacology, as above, except that birds were stimulated with a variety of nonsong stimuli that gradually depart, in their acoustic structure, from conspecific songs. Specifically, we recorded hearing-evoked responses to four stimulus classes: (1) REV, a manipulation that alters the temporal features of the stimulus but preserves its spec- 
tral components; (2) PRS, which consists of a randomization of the phase of the different spectral components of each of the four conspecific songs used; (3) FCN, which consists of bandlimited noise covering the range of zebra finch song elements $(0.1-7 \mathrm{kHz})$; and (4) FS, a single stimulus consisting of a stack of six pure tones (1-6 kHz in $1 \mathrm{kHz}$ increments), which cover the range of most zebra finch song elements (for details, see Materials and Methods).

Before pharmacological treatment, all nonsong auditory stimuli drove electrophysiological responses, to varying degrees, in NCM neurons. The median hearing-driven discharge rates during the control (predrug) session for REV, PRS, FCN, and FS were $36.2 \pm 3.1,22.86 \pm 2.4,12.74 \pm 2.8$, and $14.98 \pm 2.3$ spikes $/ \mathrm{s}$ ( \pm SE; $n=4$ birds). Similar to the pattern observed for conspecific songs, the spiking behavior of NCM neurons in response to all nonsong stimuli was not altered by unilateral vehicle infusions $(p=0.09, p=0.24, p=0.38$, and $p=0.16$, for REV, PRS, FCN, and FS, respectively). In contrast, contralateral injections of E2 markedly increased discharge rates of NCM units to all stimuli. Specifically, the mean spike rates of NCM neurons in response to REV, PRS, FCN, and FS stimuli significantly increased from $41.1 \pm 6.2,27.0 \pm 6.9,16.27 \pm 4.4$, and $19.44 \pm 7.8$ spikes $/ \mathrm{s}$ in the control (predrug) session to $102.71 \pm 14.9,86.1 \pm 11.3,45.23 \pm$ 10.42 , and $56.83 \pm 12.8$ spikes/s, respectively, after E2 $(2 \mathrm{mg} / \mathrm{ml})$ treatment $(p=0.02, p=0.03, p<0.01$, and $p=0.02 ; n=4$ birds). Such changes reflect 149.9, 218.8, 177.9, and $192.3 \%$ increases in discharge rates during the $\mathrm{E} 2$ session relative to preinjection levels (Fig. 2A).

The effects of E2 in the processing of nonsong stimuli were further quantified in the form of a response amplitude ratio, as detailed above. We found that this ratio approximated a value of 1 for all nonsong auditory stimuli in hemispheres injected with vehicle. In contrast, hemispheres injected with E2 displayed average ratios of $2.22 \pm 0.3,3.47 \pm 0.3,2.57 \pm 0.1$, and $2.48 \pm 0.2$, for REV, PRS, FCN, and FS stimuli, respectively, indicating average increases of $122,247,157$, and $148 \%$ in the response amplitudes relative to control hemispheres (Fig. 2B). These E2mediated increases in response amplitude significantly differed from amplitude ratios obtained from control hemispheres for all stimuli tested $(p=0.043, p=0.0019, p<0.001$, and $p=0.0047$ for REV, PRS, FCN, and FS, respectively). These data indicate that local increases in E2 levels augment neuronal responses to nonsong auditory stimuli in NCM.

We next examined whether TMX treatment modulated the response properties of NCM units to nonsong stimuli. We found that that the mean firing rate of NCM units significantly decreased from $32.45 \pm 9.9,20.65 \pm 3.1,11.76 \pm 1.4$, and $14.58 \pm$ 3.7 spikes/s in the predrug session to $14.9 \pm 3.9,7.4 \pm 2.1,3.92 \pm$ 1.7, and $3.49 \pm 1.7$ spikes/s during TMX treatment, when birds were stimulated with REV, PRS, FCN, and FS stimuli, respectively ( $p=0.01, p=0.003, p=0.04$, and $p<0.001 ; n=4$ birds). Relative to the predrug session, these TMX-induced changes in spiking behavior accounted for decreases of 54.1, 64.1, 66.7, and $76.1 \%$ in the discharge rate of single units to REV, PRS, FCN, and FS stimuli (Fig. 2C). A close examination of response amplitude ratios further highlighted the marked suppression of neural activity induced by local TMX treatment. Although these ratios approximated a value of 1 in control hemispheres, TMX-infused hemispheres displayed average amplitude ratios of $0.35 \pm 0.1$, $0.19 \pm 0.1,0.15 \pm 0.1$, and $0.41 \pm 0.1$ ( \pm SE) for REV, PRS, FCN, and FS conditions, respectively, indicating significant decreases of $64.1,80.8,84.1$, and $60.1 \%$ in the response amplitudes of NCM neurons to these nonsong stimuli $(p<0.001, p=0.007, p=$ 0.002 , and $p=0.006$ ) (Fig. $2 D$ ).

Together, these findings suggest that the effects of E2 in the physiology of NCM are not restricted to auditory communication stimuli but rather generalize to the processing of acoustic signals more broadly.

\section{Locally produced E2 acutely modulates auditory processing in NCM}

The findings above suggest that changes in the local levels of E2 robustly modulate the processing of auditory signals in NCM but do not conclusively establish that locally produced E2 modulates the physiology of NCM. To address this question, we infused in NCM a solution of ATD, an aromatase inhibitor, and subjected birds to both song and nonsong auditory stimuli $30 \mathrm{~min}$ after these local injections. In birds stimulated with conspecific songs, we found that ATD markedly suppressed NCM firing rates in a dose-dependent manner (Fig. 1 E). Although infusions of $100 \mu \mathrm{M}$ ATD decreased the mean discharge rates from $39.10 \pm 4.3$ spikes/s in the predrug session to $21.93 \pm 5.7$ spikes/s during the experimental session ( $\pm \mathrm{SE} ; p=0.02 ; n=4$ birds), infusions of 1 mM ATD decreased this mean from $36.86 \pm 7.1$ to $8.01 \pm 1.6$ spikes/s when comparing predrug versus during-drug sessions ( $p=0.002 ; n=3$ birds). Such changes in firing behavior represented decreases of 43.9 and $78.3 \%$ relative to the predrug state for $100 \mu \mathrm{M}$ and $1 \mathrm{mM}$ conditions, respectively (Fig. 2E). ATD treatment also induced marked decreases in the spiking behavior of NCM neurons in birds stimulated with nonsong auditory stimuli. Mean discharge rates significantly decreased from $41.07 \pm 5.2,21.37 \pm 2.9,11.84 \pm 2.2$, and $17.78 \pm 3.2$ in the control session to $18.95 \pm 5.5,11.28 \pm 3.4,4.86 \pm 6.1$, and $8.82 \pm 8.1$ during ATD treatment $(100 \mu \mathrm{M})$, when animals were stimulated with REV, PRS, FCN, and FS stimuli, respectively $(p=0.008, p=0.03, p=0.02$, and $p=0.04 ; n=4$ birds). These ATD-mediated changes amounted to decreases of $53.8,47.2,58.9$, and $50.4 \%$ in the discharge rates associated with REV, PRS, FCN, and FS stimuli, respectively, relative to the predrug session (Fig. 2E).

We further quantified the effects of ATD on song- and nonsong-evoked responses by calculating a post/pre amplitude ratio, as detailed above. We detected significant decreases in this ratio when comparing control and experimental hemispheres. Whereas the ratios calculated for control hemispheres invariably approached a value of 1 (indicating no effect of vehicle), average ratios obtained for experimental hemispheres were $0.38 \pm 0.03$ and $0.21 \pm 0.1$ for $100 \mu \mathrm{M}$ and $1 \mathrm{~mm}$ ATD, respectively, when birds were stimulated with conspecific songs (Fig. $2 F$ ). Such changes, which statistically differed from control injected hemispheres ( $p<0.001$ for both conditions), approximately reflect 63.4 and $78.1 \%$ decreases in the amplitude of song-driven responses. Similar to what was observed with conspecific songs, we found that the amplitude ratios associated with nonsong auditory stimuli also underwent significant decreases relative to control levels. Specifically, we found that the amplitude ratios for REV, PRS, FCN, and FS conditions in ATD-treated hemispheres (100 $\mu \mathrm{M}$ ) averaged $0.42 \pm 0.1,0.44 \pm 0.1,0.48 \pm 0.1$, and $0.44 \pm 0.01$, respectively, which reflected significant decreases of $58.3,52.2$, 51.3 , and $57.6 \%$ from control response amplitudes $(p=0.0005$, $p=0.02, p=0.008$, and $p=0.0004$ for REV, PRS, FCN, and FS, respectively) (Fig. $2 F$ ). Together, these findings provide direct evidence that locally generated E2 robustly modulates the processing of song and nonsong auditory stimuli in the NCM of awake zebra finches. 

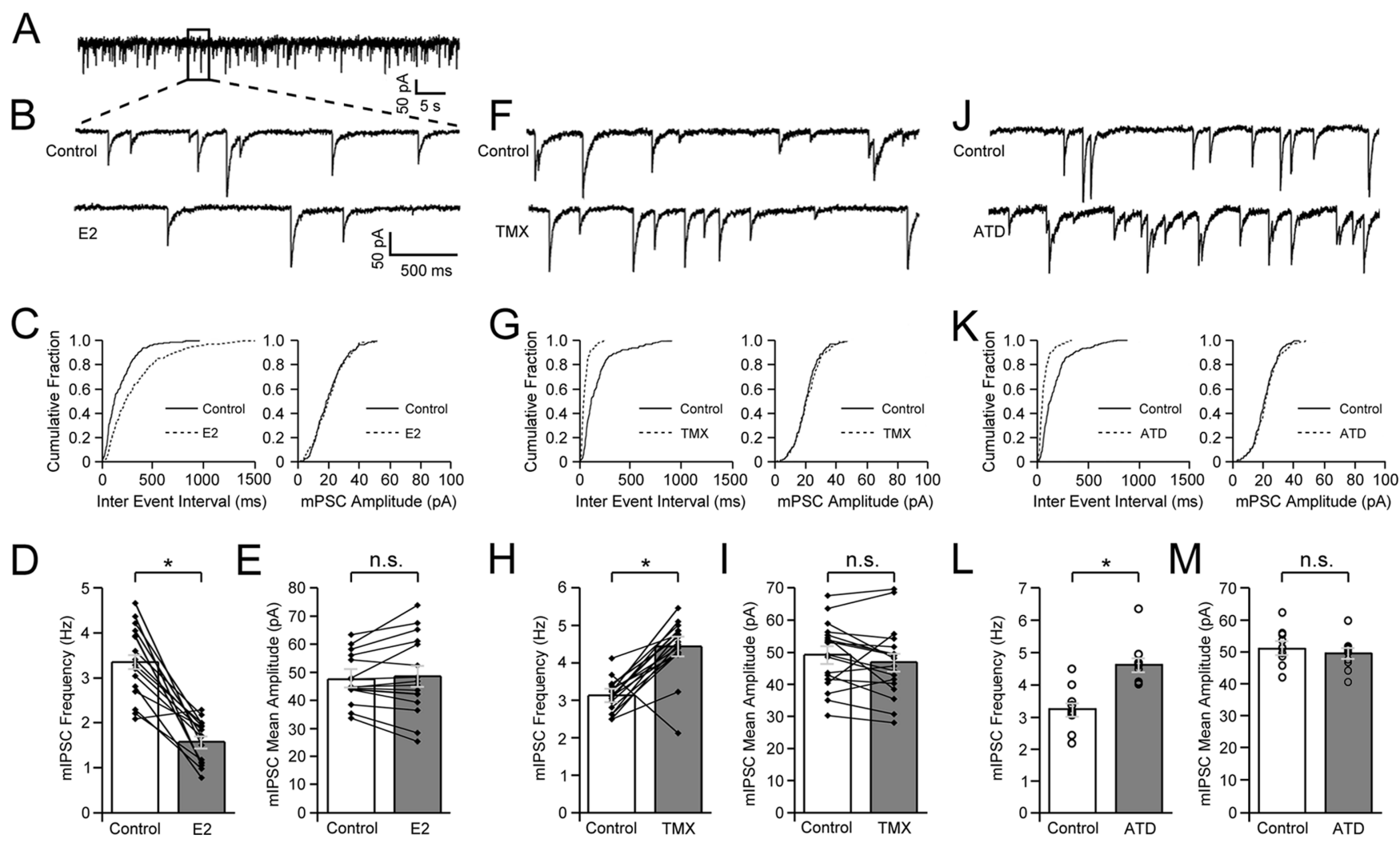

Figure 3. E2 increases NCM neuronal responsiveness by suppressing inhibitory neurotransmission. $\boldsymbol{A}$, Pharmacologically isolated mIPSCs are expressed at relatively high frequency in NCM neurons. Depicted is a 1-min-long trace obtained from a representative NCM neuron illustrating recording stability and the overall frequency of mIPSCs in our slice preparation. $\boldsymbol{B}$, mIPSCs recorded from a representative NCM neuron before (top trace) and after (bottom trace) application of E2 (50 nM) to the recording bath. C, Cumulative frequency histograms of the interevent intervals (left) and $\mathrm{mIPSC}$ amplitudes (right). $\boldsymbol{D}, \boldsymbol{E}$, Effects of E2 in the frequency $(\boldsymbol{D})$ and amplitude $(\boldsymbol{E})$ of $\mathrm{mIPSC}$. Means are represented by the vertical bars for each condition, and diamonds illustrate values obtained for each individual cell that contributed to that mean; SE is indicated by the light gray error bars. Although a significant E2-mediated decrease in the frequency of mIPSCs was detected, no changes were observed in their mean amplitude. $\boldsymbol{F}$, Representative traces illustrating mIPSCs before (top trace) and after (bottom trace) application of TMX ( $2 \mu \mathrm{M})$ to the recording bath. $\mathbf{G}$, Cumulative frequency histograms depicting the interevent intervals (left) and amplitude of the mIPSCs. $\boldsymbol{H}, \boldsymbol{I}$, Bar graphs illustrating the quantitative differences in the mean frequency $(\boldsymbol{H})$ and amplitude $(\boldsymbol{I})$ of $\mathrm{mIPSC}$ as a result of TMX treatment. TMX significantly increased the frequency of mIPSCs with no changes detected in mean mIPSC amplitude. J, Traces from two representative cells obtained from adjacent NCM slices incubated for $30 \mathrm{~min}$ in either aCSF (top trace) or aCSF plus ATD (20 $\mu$; ; bottom trace). $\boldsymbol{K}$, Cumulative frequency histograms of the interevent intervals (left) and mIPSC amplitudes (right). $\boldsymbol{L}, \boldsymbol{M}$, ATD treatment significantly increased the mean frequency of mIPSCs in NCM neurons in the absence of changes in mIPSC amplitude. Means are indicated by the vertical bars, and open circles illustrate the values obtained for each cell that contributed to that mean. Given that control and ATD recordings were obtained from adjacent slices, and therefore different cells, no connecting lines are shown between these conditions; SE is indicated by the light gray error bars. ${ }^{*} p<0.0001$.

\section{E2 increases neuronal responsiveness by suppressing $\mathrm{GABA}_{\mathrm{A}}$-mediated inhibition}

The results above indicate that local E2 acts to increase NCM neuronal responsiveness, although the specific mechanisms underlying such changes are unknown. We have shown previously that virtually all NCM neurons receive highly dense GABAergic input exclusively through $\mathrm{GABA}_{\mathrm{A}}$ receptors and that this inhibition is central to the encoding and temporal organization of song-evoked responses in NCM (Pinaud et al., 2008c). Based on these previous observations, we hypothesized that E2 increases song-evoked responses by impacting GABAergic transmission in NCM neurons. To investigate this possibility, we conducted whole-cell patch-clamp recordings in a slice preparation containing NCM that we previously developed and studied (Pinaud et al., 2004, 2008c). To assess whether E2 impacts inhibitory transmission in NCM, we pharmacologically isolated mIPSCs, as we have done previously (Pinaud et al., 2004, 2008c) (for details, see Materials and Methods) (Fig. 3A) (supplemental Fig. 3, available at www.jneurosci.org as supplemental material). We found that application of E2 (50 nM) to the recording bath significantly decreased the frequency of mIPSCs from $3.36 \pm 0.2$ to $1.58 \pm 0.1$ $\mathrm{Hz}$ (mean $\pm \mathrm{SE} ; p<0.0001 ; n=16$ neurons from 7 birds), which reflects an average $52.9 \%$ decrease in the mean frequency of these GABAergic events (Fig. $3 B-D$ ). These mIPSCs were mediated through $\mathrm{GABA}_{\mathrm{A}}$ receptors, because they were completely abolished by coapplication of bicuculline $(20 \mu \mathrm{M})$, a selective $\mathrm{GABA}_{\mathrm{A}}$ receptor antagonist (data not shown). E2 treatment did not result in changes in mIPSC amplitude (control, $47.5 \pm 2.0 \mathrm{pA}$; E2, $48.6 \pm 3.6 \mathrm{pA} ; p=0.75$ ) (Fig. $3 C, E$ ). To address whether $\mathrm{E} 2$ also impacted glutamatergic neurotransmission in NCM, we pharmacologically isolated mEPSCs in NCM neurons, as we have done previously (Pinaud et al., 2008c), and applied E2, at the same concentration, to the recording bath. Neither the frequency (control, $1.2 \pm 0.2 \mathrm{~Hz}$; E2, $1.1 \pm 0.19 \mathrm{~Hz} ; p=0.46$ ) nor the amplitude (control, $37.3 \pm 2.9 \mathrm{pA}$; E2, $35.8 \pm 3.2 \mathrm{pA} ; p=0.63$; $n=12$ cells from 4 birds) of mEPSCs were impacted by E2 treatment.

We next tested whether modulation of $\mathrm{E} 2$ receptors with TMX effects impacted inhibitory neurotransmission within NCM circuitry. Application of TMX $(2 \mu \mathrm{M})$ to the recording bath led to a marked increase in the frequency of mIPSCs (control, $3.13 \pm 0.1$ $\mathrm{Hz}$; TMX, $4.44 \pm 0.2 \mathrm{~Hz} ; p<0.0001 ; n=18$ neurons from 9 birds) (Fig. $3 F-H)$. TMX treatment did not impact the amplitude of these miniature events (control, $49.1 \pm 2.4$ pA; TMX, $46.7 \pm$ 
$2.7 \mathrm{pA} ; p=0.55$ ) (Fig. 3G,I). Finally, TMX at the same concentration did not impact either the frequency (control, $0.9 \pm 0.5$ $\mathrm{Hz}$; TMX, $1.1 \pm 0.2 \mathrm{~Hz} ; p=0.31$ ) or amplitude (control, $38.9 \pm$ $3.1 \mathrm{pA}$; TMX, $36.1 \pm 2.8 \mathrm{pA} ; p=0.15 ; n=14$ cells from 6 birds) of miniature excitatory neurotransmission in NCM.

The results detailed above indicate that TMX alone increases mIPSC frequency in our NCM slice preparation. Importantly, however, most examples available in the literature of rapid E2 action in neuronal electrophysiological properties in vitro have not been sensitive to ER antagonists in the absence of exogenous E2 (Rudick and Woolley, 2003; Rudick et al., 2003; Hu et al., 2007). It is possible, therefore, that the $\mathrm{E} 2$ levels produced by our slices are sufficient to modulate neurotransmission such that these E2 effects can be blocked by TMX. To address this possibility, we incubated NCM slices in a solution containing ATD (20 $\mu \mathrm{M}$ ) for $30 \mathrm{~min}$ and subsequently pharmacologically isolated mPSCs, as detailed above. Compared with control slices, which exhibited a mean mIPSC frequency of $3.23 \pm 0.2 \mathrm{~Hz}$, slices preincubated in ATD displayed a mean frequency of $4.62 \pm 0.2 \mathrm{~Hz}$ (Fig. $3 J-L)$. These two conditions significantly differed $(p=$ $0.028 ; n=11$ neurons from 3 birds), indicating that E2 produced in our slice preparation modulates basal neurotransmission of NCM neurons. No effects were detected in mIPSC amplitude across these conditions (control, $51.4 \pm 1.6 \mathrm{pA}$; ATD, $49.4 \pm 1.4$ pA; $p=0.46$ ) (Fig. $3 K, M)$. We next assessed the effects of TMX on mIPSC frequency and amplitude in slices subjected to preincubation in ATD. We found that TMX application to the recording bath failed to further impact either the frequency or amplitude of mIPSCs (ATD only, $4.4 \pm 0.3 \mathrm{~Hz}$ and $48.2 \pm 2.1 \mathrm{pA}$; ATD plus TMX, $4.51 \pm 0.2 \mathrm{~Hz}$ and $49.7 \pm 1.9 \mathrm{pA} ; p=0.31$ and $p=$ 0.18 for frequency and amplitude, respectively; $n=14$ cells from 4 birds). These findings suggest that the TMX-induced increase in mIPSC frequency depends on endogenously generated E2. Preincubation of slices in ATD failed to impact either frequency (control, $1.2 \pm 0.4 \mathrm{~Hz}$; ATD, $1.0 \pm 0.3 \mathrm{~Hz} ; p=0.16$ ) or amplitude (control, $39.3 \pm 3.3 \mathrm{pA}$; ATD, $35 \pm 2.8 \mathrm{pA} ; p=0.09 ; n=12$ cells from 4 birds) of mEPSCs, suggesting that local blockade of E2 synthesis does not impact glutamatergic transmission.

Overall, the results of our patch-clamp experiments indicate that E2 directly increases the neuronal activity of NCM by suppressing local $\mathrm{GABA}_{\mathrm{A}}$-mediated inhibitory transmission.

\section{Local E2 is necessary for MAPK-dependent, hearing-driven gene expression}

The results described above indicate that E2 modulates the physiology of NCM neurons during the processing of auditory signals. These findings are consistent with reports obtained in multiple preparations, suggesting that E2 may acutely impact neuronal physiology through nongenomic mechanisms (McEwen and Alves, 1999; McEwen, 2002; Woolley, 2007). It is also well established that activated ERs impact long-term neuronal physiology by regulating gene expression programs. Such effects of E2 on gene expression may occur via cis-regulatory or trans-activational mechanisms and, as more recently shown, through direct actions on the activation of a variety of signal transduction pathways (Marino et al., 2006; Woolley, 2007; McCarthy, 2008; Safe and Kim, 2008). It is plausible, therefore, that E2 may not only impact the electrophysiological properties of NCM neurons but also its experience-regulated gene expression programs. In fact, auditory experience drives the expression of activity-dependent genes in NCM, most of which are regulated by the MAPK pathway, including the IEGs zenk, c-fos, and arc (Cheng and Clayton, 2004; Velho et al., 2005; Pinaud et al., 2008a). Activation of the MAPK pathway in NCM is required for the formation of auditory memories necessary for vocal learning (London and Clayton, 2008) and is thought to represent a central event in the cascade of cellular processes leading to neuronal plasticity associated with auditory learning and, perhaps, memory formation in the adult NCM (Mello et al., 2004; Velho et al., 2005; Mello and Pinaud, 2006; Pinaud and Terleph, 2008). Importantly, research conducted in other preparations indicates that E2 may directly modulate the activity of the MAPK pathway, raising the possibility that auditory-driven gene expression in NCM may be regulated by local E2 levels (McEwen and Alves, 1999; Mannella and Brinton, 2006; Jover-Mengual et al., 2007). To test this possibility, we injected TMX or E2 into the NCM in one hemisphere of awakerestrained animals and vehicle in the contralateral hemisphere, which enables each animal to serve as its own control (see Materials and Methods; importantly, no interhemispheric connections occur in NCM). Animals were then stimulated with song playbacks (stimulated) or maintained in silence (unstimulated controls) (Fig. 4A). A fluorescence in situ hybridization protocol developed by our group was used to assess the expression levels of two regulatory and one effector song-inducible IEGs: zenk, c-fos, and $\operatorname{arc}$ (Pinaud et al., 2008b). Importantly, we and others previously demonstrated that the activation of the MAPK pathway is necessary for the expression of all three IEGs in the songbird NCM (Cheng and Clayton, 2004; Velho et al., 2005).

In song-stimulated animals, unilateral infusion of TMX markedly decreased hearing-induced expression of all three IEGs (Fig. 4B-E) (supplemental Fig. 1, available at www.jneurosci.org as supplemental material). Relative to vehicle-injected hemispheres, which exhibited an average of $1273 \pm 53.8$ neurons/ $\mathrm{mm}^{2}$ (mean $\pm \mathrm{SE} ; n=5$ birds), the mean number of zenkpositive cells in TMX-treated hemispheres amounted to $524 \pm$ $61.7(p<0.0001)$ (Fig. $4 F)$. This change reflects an average $58.8 \%$ decrease in the number of zenk-positive cells after TMX treatment. Likewise, TMX triggered average decreases from $1487 \pm 70.9$ to $213 \pm 45.7$ and from $1293 \pm 78.2$ to $243 \pm 43.5$ in the number of c-fos- and arc-expressing cells, respectively, which accounted for a mean 85.6 and $81.2 \%$ reduction in the population of neurons expressing these genes $(p<0.0001$ for both genes) (Fig. 4G-H). No significant changes were detectable when comparing vehicle-injected versus non-injected hemispheres (data not shown), for all genes studied; therefore, vehicle injections do not interfere with the normal song-induced expression of these IEGs. These findings suggest that blockade of ER activation significantly suppresses the hearing-regulated induction of multiple MAPK-dependent genes. Based on these results, we postulate that local E2 is necessary for the normal induction of multiple song-regulated genes in NCM.

We next tested whether unilateral increases in E2 levels interfered with the song-induced expression of all three MAPKdependent IEGs. After this manipulation, we detected no changes in the number of cells expressing all three IEGs in the E2-infused hemispheres relative to the vehicle-injected hemispheres (supplemental Figs. 1, 4, available at www.jneurosci.org as supplemental material). Although in control hemispheres an average of $1110 \pm 45.9,1431 \pm 69.1$, and $1378 \pm 79.5$ neurons expressed zenk, c-fos, and arc per square millimeter, respectively, these values were not significantly different from the E2-treated hemisphere, in which $1151 \pm 32.3,1465 \pm 82.6$, and $1451 \pm 67.1$ cells expressed the mRNA for zenk, $\mathrm{c}$-fos, and arc per the same unit area, respectively ( $p=0.20, p=0.75$, and $p=0.39 ; n=4$ birds $)$ (supplemental Fig. 4, available at www.jneurosci.org as supplemental material). More than $95 \%$ of the overall neuronal popu- 
lation of NCM expresses these IEGs in response to playbacks of three or more songs (C. V. Mello and R. Pinaud, unpublished observations). We therefore interpret our results to suggest that increases in local E2 levels, combined with song stimulation, may not recruit a significant number of additional cells to undergo IEG induction, presumably because song alone drives IEG expression in a near-maximal neuronal population in NCM (ceiling effect).

E2 is sufficient to induce MAPKdependent gene expression in the absence of auditory stimulation Our experiments above indicate that E2 is necessary for song-driven IEG expression. To test whether E2 is also sufficient for their induction, we unilaterally injected E2 in sound-isolated animals and infused vehicle in the contralateral hemisphere (Fig. $5 A$ ) (supplemental Fig. 1, available at www.jneurosci.org as supplemental material). Remarkably, we found that infusions of E2 triggered a robust induction of all three IEGs in the injected hemisphere (Figs. 5B-D). Although vehicle-injected hemispheres exhibited a negligible number of IEG-expressing neurons ( $90 \pm 14.6$, $60 \pm 16.3$, and $125 \pm 16.1$ cells $/ \mathrm{mm}^{2}$ for zenk, c-fos, and arc, respectively; $n=6$ birds), E2-treated hemispheres underwent a significant induction of all MAPKdependent genes studied (1315 \pm 35.6 , $1522 \pm 75.2$, and $1455 \pm 121.6$ cells $/ \mathrm{mm}^{2}$ for zenk, c-fos, and arc, respectively; $p<$ 0.0001 for all three genes) (Fig. $5 E-G$ ). In fact, E2-treated hemispheres of soundisolated animals exhibited IEG induction levels that were not statistically different from vehicle-treated hemispheres of songstimulated birds $(p=0.56, p=0.48$, and $p=0.24$, for zenk, $c$-fos, and arc, respectively), suggesting that E2 infusions drive MAPK-dependent gene expression to levels similar to those triggered by auditory stimulation itself. These results indicate that local E2 levels are not only necessary, but also sufficient, to drive the expression of multiple target genes regulated by the MAPK pathway. Importantly, our results suggest that the expression of these "plasticity"-associated IEGs can be driven in complete absence of sensory input, by local increases in the levels of E2.

\section{Endogenous E2 strongly regulates MAPK-dependent, hearing-driven gene expression}

The studies above suggest that exogenous E2 robustly modulate MAPK-dependent gene expression in the NCM of awake zebra finches. We next tested whether locally produced $\mathrm{E} 2$ also contributes to the normal song-induced expression of plasticity-associated genes. To this end, we injected ATD unilaterally, and vehicle was injected in the contralateral hemisphere. Thirty minutes after the injections, birds were stimulated with conspecific song playbacks, as detailed above (see Materials and Methods) (Fig. 6A).

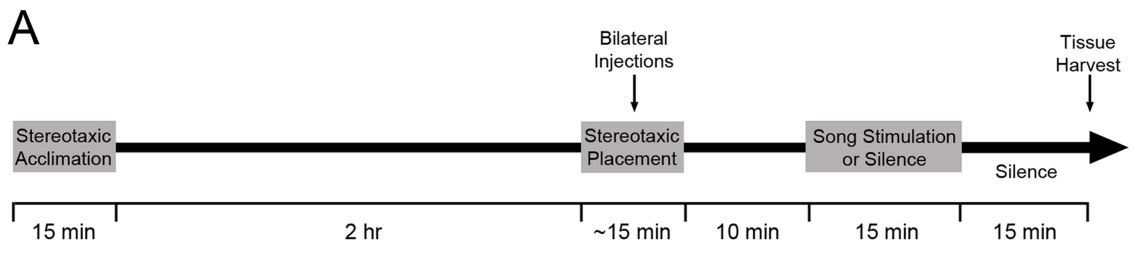

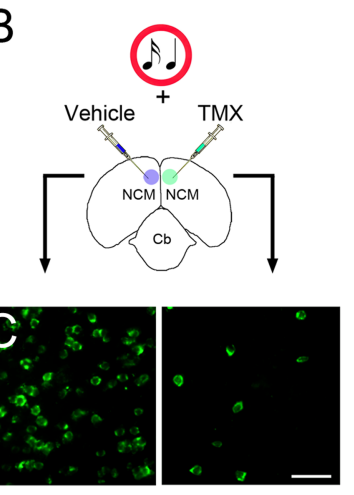

zenk

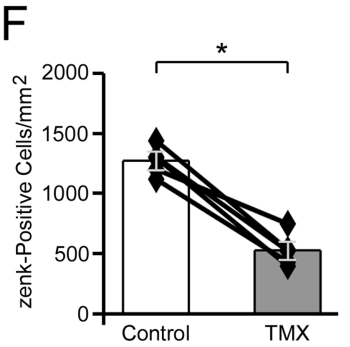

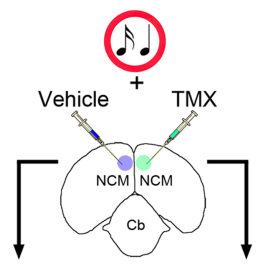

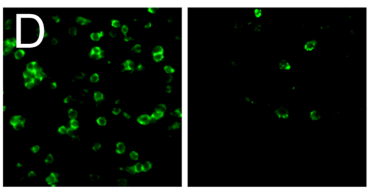

C-fos

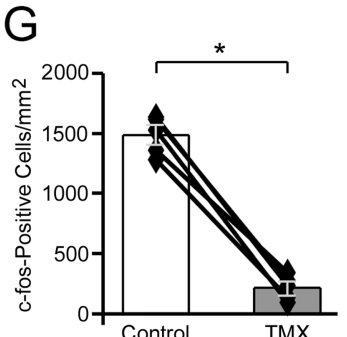

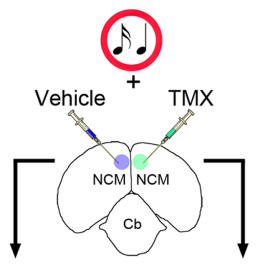

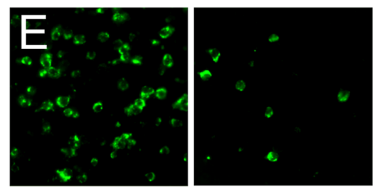

$\operatorname{arc}$

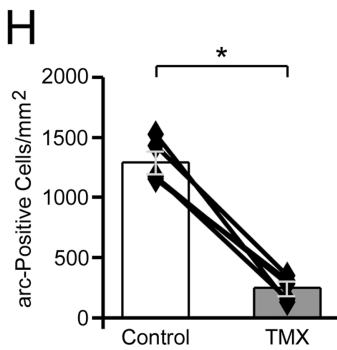

Figure 4. Intracerebral infusions of TMX, but not vehicle, in the NCM of awake birds largely suppress song-induced, MAPKstrained animals. Represented here are the procedures performed on the day of the injection but not the acclimation sessions the previous day (see Materials and Methods). B, Camera lucida drawings of a coronal section through the zebra , and $\operatorname{arc}(\boldsymbol{E})$, as revealed by fluorescence in situ hybridization (Pinaud et al., 2008b). Importantly, the images shown for vehicle

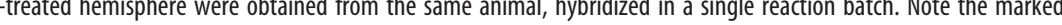
densities in vehicle- versus TMX-injected hemispheres, for zenk $(\boldsymbol{F}), \boldsymbol{c}$-fos $(\boldsymbol{G})$, and $\operatorname{arc}(\boldsymbol{H})$, in the brains of song-stimulated animals. Vertical bars illustrate group means for each gene, and diamonds indicate the values obtained for each individual bird that contributed to that mean; SE is indicated by the light gray error bars. Note that auditory experience drives a marked induction of all genes in the vehicle-injected hemispheres, but a significant decrease in the number of IEG-expressing neurons is observed for TMX-injected hemispheres. ${ }^{*} p<0.0001$. Scale bar, $25 \mu \mathrm{m}$. Cb, Cerebellum.

Unilateral infusion of ATD significantly decreased the hearing-induced expression of zenk, c-fos, and arc (Fig. 6B-E): whereas vehicle-treated hemispheres exhibited an average of $1268 \pm 32.8,1297 \pm 105.5$, and $1272 \pm 77.5$ neurons $/ \mathrm{mm}^{2}$, ATD-injected hemispheres averaged $340 \pm 18.9,293 \pm 19.6$, and $303 \pm 29.1$ neurons $/ \mathrm{mm}^{2}$ that were positive for zenk, c-fos, and arc, respectively ( $\pm \mathrm{SE} ; p<0.001$ for all genes; $n=5$ birds) (Fig. $6 \mathrm{~F}-\mathrm{H})$. These ATD-induced changes accounted for 73.1, 77.4, and $76.1 \%$ reductions in the neuronal populations expressing each of these genes. These findings indicate that locally produced E2 significantly contributes to regulating the song-induced expression of multiple plasticity-associated genes in the NCM of adult songbirds.

\section{Discussion}

Our work demonstrated that E2, a classic sex steroid hormone, directly and rapidly influences auditory processing in a central 
A

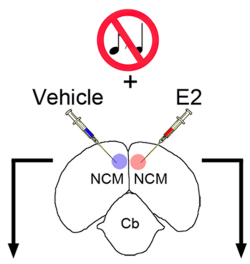

B

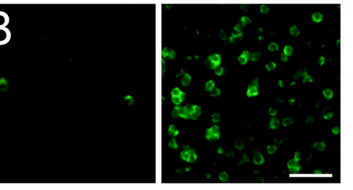

zenk

E

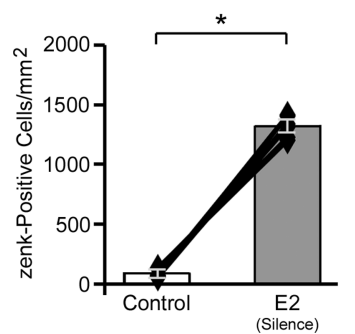

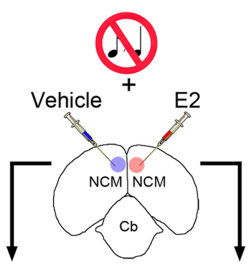

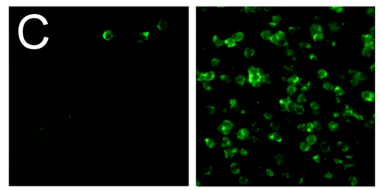

c-fos

F

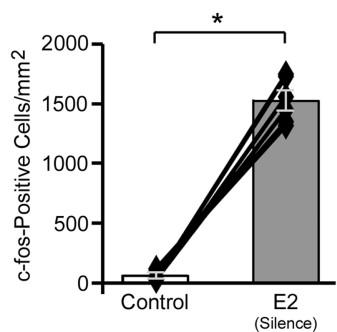

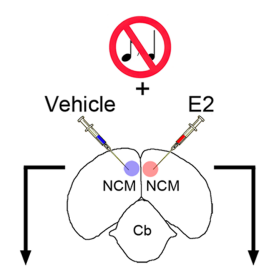

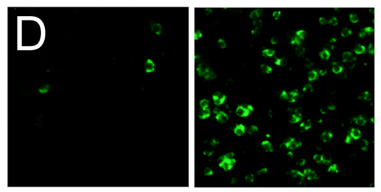

$\operatorname{arc}$

$G$

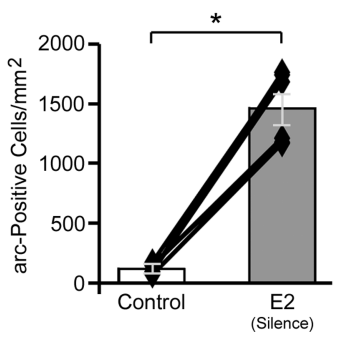

Figure 5. Intracerebral injections of E2, but not vehicle, trigger MAPK-dependent gene expression in the absence of auditory stimulation. $\boldsymbol{A}$, Schematic representation of the experimental design for bilateral injections represented as camera lucida drawings of a coronal section. Awake birds were injected with vehicle in one hemisphere, with E2 in the other, and remained in complete silence until the end of the experiment. $\boldsymbol{B}-\boldsymbol{D}$, Photomicrographs of representative brain sections subjected to fluorescence in situ hybridization with riboprobes directed at zenk $(\boldsymbol{B}), \boldsymbol{c}-\operatorname{fos}(\boldsymbol{C})$, and $\operatorname{arc}(\boldsymbol{D})$. Note that, in vehicle-injected hemispheres of acoustically isolated animals, the expression levels of each IEG is extremely low. Conversely, the expression of all three genes is markedly induced after a single restricted $\mathrm{E} 2$ injection in the contralateral hemisphere in the awake bird. $\boldsymbol{E}-\boldsymbol{G}$, Quantitative assessment of neuronal densities in vehicle- versus E2-injected hemispheres for zenk $(\boldsymbol{E}), \boldsymbol{c}$-fos $(\boldsymbol{F})$, and arc $(\boldsymbol{G})$ in the brains of sound-isolated (silence) animals. Bars show group averages for each gene, and diamonds illustrate data obtained for each subject that contributed to that mean; SE is indicated by the light gray error bars. Note that, in the absence of sensory experience, the infusion of 2 , but not vehicle, drives a marked induction of the three IEGs in NCM. ${ }^{*} p<0.0001$. Scale bar, $25 \mu \mathrm{m}$. Cb, Cerebellum.

auditory area of a highly social songbird species. Consistent with the previous description of E2-synthesizing and E2-sensitive neurons in NCM (Shen et al., 1995; Bernard et al., 1999; Metzdorf et al., 1999; Saldanha et al., 2000; Fusani et al., 2001; Saldanha and Coomaralingam, 2005; Pinaud et al., 2006), we observed marked effects of both exogenously derived and locally produced E2 during the processing of song and nonsong auditory stimuli. Indeed, local increases in E2 levels significantly enhanced the responsiveness, and consequently the firing rates, of NCM neurons in the awake songbird. These changes in spiking behavior were virtually instantaneous, suggesting that E2 modulates NCM neuronal physiology via nongenomic mechanisms. To our knowledge, these rapid effects of $\mathrm{E} 2$ in vivo, during the processing of sensory information, have not been reported previously and highlight the fact that sex steroid hormones may impact neuronal physiology on a timescale compatible with rapid neuromodulators and/or neurotransmitters.

\section{Physiological impact of E2 in auditory processing}

One potential limitation of our study is that the concentrations of exogenous E2 infused into NCM (and likely the "effective" local concentrations of E2) may depart from physiological levels, although this topic is currently under significant debate in the field. Whereas plasma levels of E2 in the zebra finch approximate 500 pM in both males and females (Schlinger and Arnold, 1991; Cornil et al., 2006), local levels of this hormone in NCM were recently reported to average $\sim 55 \mathrm{pm}$ but can rapidly increase to $92 \mathrm{pm}$ during social interactions (RemageHealey et al., 2008). Caution, however, is warranted in the interpretation that brain E2 levels are lower than plasma concentrations in the zebra finch. In fact, E2 concentrations obtained from dialysis measurements depend on the dynamics of the exchange between interstitial fluid and the dialysis fluid and, therefore, may not directly represent the actual hormone concentrations in the brain. This interpretation is consistent with previous findings indicating that E2 levels are significantly higher in the jugular than in the carotid of zebra finches, suggesting that estrogens produced in the brain are indeed released in the entire body (Schlinger and Arnold, 1992). Importantly, it is also possible that the effective concentration of estrogens at the synaptic level (aromatase-positive synapses) may be markedly higher than those levels measured in the plasma or even in the brain of zebra finches (Cornil et al., 2006). Taking these considerations into account, it is plausible that our experimental treatments produced local E2 concentrations that are within the physiological range in NCM. In contrast, if we interpret our findings conservatively, it may be possible that our concentrations are supraphysiological. Thus, the effects of exogenous E2 treatment described here may be exaggerated relative to the modulatory strength occurring as a function of endogenous E2 levels in NCM. Importantly, however, we showed that local inhibition of aromatase, which is known to decrease local physiological levels of endogenous E2 (Remage-Healey et al., 2008), also triggered rapid and marked effects on NCM neuronal auditory responses. Consistent with this observation, we also found that TMX treatment significantly decreased hearing-evoked responses, suggesting that interference with physiological levels of E2 acutely and profoundly modulate auditory responses in NCM. Together, these findings suggest that alterations in local E2 levels provide a powerful mechanism for the rapid regulation of electrophysiological properties of NCM neurons during the auditory processing of acoustic signals.

\section{Estradiol as a rapid regulator of neuronal excitability and} sensory processing

E2 has been clearly shown to impact neuronal physiology in a number of preparations and experimental models. The mechanisms by which such effects occur, however, are quite varied, can involve changes in either excitatory or inhibitory transmission, and have been most extensively characterized in the mammalian hypothalamus and hippocampus (McEwen and Alves, 1999; Foy, 2001; McEwen, 2002; Woolley, 2007). For example, in the hippocampal CA1 subfield, low E2 concentrations (100 pM to 100 nM) were shown to increase synaptic excitability by enhancing the magnitude of AMPA and kainate glutamate receptor responses (Wong and Moss, 1992; Gu and Moss, 1996; Kumar and Foster, 2002). Similarly, the amplitude of NMDA currents has been reported to sharply increase after E2 treatment (Foy et al., 1999; 
Foy, 2001), a finding that is consistent with E2-mediated enhancement of long-term potentiation in the hippocampus (Bi et al., 2000). In the hypothalamus, E2 has also been shown to potentiate excitatory responses of specific neuronal populations. In the ventromedial nucleus, for instance, neurons exposed to E2 become more excitable through a combined enhancement of inward $\mathrm{Na}^{+}$currents and the attenuation of outward $\mathrm{K}^{+}$currents (Kow et al., 2006). In our study, E2 did not affect mEPSCs under the conditions tested but markedly impacted $\mathrm{GABA}_{\mathrm{A}}$-mediated transmission in NCM. Consistent with this observation, significant precedent also exists for E2-mediated changes in inhibitory neurotransmission. For instance, E2 was shown to alter expression levels and subunit composition of $\mathrm{GABA}_{\mathrm{A}}$ receptors in various structures of the limbic system (Maggi and Perez, 1984; Schumacher et al., 1989; Herbison and Fénelon, 1995; Herbison, 1997). Our results show that E2 significantly and rapidly impacts GABAergic transmission in NCM, but it is presently unclear whether such effects on $\mathrm{GABA}_{\mathrm{A}}$ currents are mediated through similar mechanisms as those observed in the limbic system, namely, changes in the expression patterns of $\mathrm{GABA}_{\mathrm{A}}$ receptors. Given that E2 affects $\mathrm{GABA}_{\mathrm{A}}$ currents almost instantaneously in NCM, it is highly improbable that these effects are mediated through changes in receptor composition and/or expression. Rapid E2 changes in $\mathrm{GABA}_{\mathrm{A}}$-mediated currents may more likely involve a direct allosteric modulation of $\mathrm{GABA}_{\mathrm{A}}$ receptor function by activated ERs or a fast-acting second-messenger system. Importantly, however, our findings show that E2 significantly impacts the frequency, but not amplitude, of mIPSCs, suggesting that E2 likely exerts an effect on the release probability of GABA in inputs to NCM neurons.

We also showed that TMX treatment increased the frequency of mIPSCs in NCM neurons. TMX is a selective ER modulator given that it may act as either an antagonist or an agonist, depending on the presence of specific cofactors and on the conformation of ERs (MacGregor and Jordan, 1998; Woolley, 2007). Given that TMX treatment in our preparation yielded effects that were opposite from E2, we interpret these findings to suggest that TMX likely acted as an antagonist in NCM neurons. Notably, TMX appears to be an inert molecule; it is a metabolite of TMX (4-hydroxy-tamoxifen) that may impact ER function (Woolley, 2007). Even though in vivo experiments routinely use TMX, a significant fraction of in vitro studies in the literature require 4-hydroxy-tamoxifen for modulation of cellular physiology (Dick and Sanders, 2001; Kelly et al., 2003). The presence or lack of TMX effect in brain slices appears to depend on the experimental system and preparations being studied. In NCM, TMX triggered robust effects in NCM neurons, suggesting that this compound is processed in our slice preparation, a finding that is consistent with results obtained in other preparations (Lin et al., 2007; Zhang et al., 2009).

Previous research from our group demonstrated that $\mathrm{GABA}_{\mathrm{A}}$ mediated inhibition is prevalent in NCM and required for the adequate encoding and temporal organization of song-evoked responses (Pinaud et al., 2008c). These findings, along with the results presented here, raise the possibility that E2 may directly shape auditory responses in NCM by regulating GABAergic tone locally. In subsequent studies, it will, therefore, be important to determine the factors that regulate E2 levels in NCM. For example, it will be critical to establish whether the local concentrations of E2 or the expression levels of ERs in NCM are modulated by auditory experience. If detected, such changes could be mediated through a number of mechanisms that include, but are not limited to, activity-dependent changes in the expression levels of aromatase and/or ERs or even song-induced changes in aromatase catalytic activity. Such possibilities could provide a means for E2 to rapidly influence the neuronal physiology of NCM dur- 
ing sensory processing and, consequently, impact the perceptual processing of songs. Regardless of the specific mechanisms by which auditory experience may impact local E2 levels, our findings provide evidence for a direct and local role of a classic steroid hormone in auditory processing in the vertebrate brain. These findings are consistent with a recent report indicating that social interactions in songbirds trigger a rapid and robust increase in E2 levels in NCM (Remage-Healey et al., 2008).

\section{Regulation of plasticity-associated gene expression by estradiol}

We also showed that E2 is both necessary and sufficient for the induction of MAPK-dependent IEG expression in NCM. Specifically, we found that local modulation of ERs with TMX significantly decreased song-induced expression of three IEGs and that infusions of E2 into the NCM of sound-isolated animals drove a robust expression of these MAPK target genes, to levels comparable with song-stimulated animals. In addition, local blockade of aromatase activity in NCM led to a significant decrease in the population of neurons that exhibits song-induced expression of these MAPK-dependent genes. A large body of evidence implicates the activation of the MAPK cascade as a fundamental mechanism controlling various forms of synaptic plasticity, including those supporting learning and memory formation (Sweatt, 2001; Thomas and Huganir, 2004). Consistent with this view, phosphorylation of extracellular signal-regulated kinase (a member of the MAPK pathway) and the induction of multiple MAPKdependent, plasticity-associated genes (e.g., zenk, c-fos, and $a r c$ ) have been reported in NCM after auditory experience (Cheng and Clayton, 2004; Velho et al., 2005; Pinaud et al., 2008a). Importantly, local blockade of MAPK pathway activation in the songbird NCM was shown recently to severely impact the formation of auditory memories required for vocal learning (London and Clayton, 2008). Our current findings show that E2 levels in NCM are central to the engagement of such gene expression programs. Although a detailed characterization of the molecular interactions mediating E2 effects in IEG expression in NCM will await future studies, those presumably occur at the level of, or upstream from, the MAP kinase MEK 1/2, given that this enzyme is necessary for song-induced expression of zenk, c-fos, and arc in NCM (Cheng and Clayton, 2004; Velho et al., 2005). In fact, activated ERs have been shown previously to indirectly regulate transcriptional activity by interacting with protein kinases in the cytosol, including protein kinase A (Aronica et al., 1994; Abrahám and Herbison, 2005), the phosphatidylinositol 3-kinase (Znamensky et al., 2003; Schwarz et al., 2008), and, importantly, MEK 1/2 (Singh et al., 1999). Additional studies provide evidence for direct interactions between activated ERs and the MAPK pathway (McEwen and Alves, 1999; Mannella and Brinton, 2006; Jover-Mengual et al., 2007; Woolley, 2007), suggesting that the E2 actions on gene expression of NCM detected in our work results from similar mechanisms rather than through classic ERmediated genomic responses.

Apart from the specific mechanisms by which E2 impacts transcriptional activity, our findings suggest that a sex steroid hormone may directly impact plasticity-related processes associated with auditory experience, perhaps including the formation of auditory memories. Importantly, we showed that IEG expression in NCM can be induced in the absence of sensory input. These surprising findings indicate that molecular scripts associated with synaptic plasticity can be manipulated in NCM through alterations in intrinsic E2 levels and potentially harnessed to im- prove functionality of this auditory station during auditorybased behaviors.

\section{Estradiol as a potential modulator of auditory perception}

It is clear that the plasma levels of gonadal steroids impact a variety of social behaviors, including the perception of, and responsiveness to, sociosexual signals (Sisneros et al., 2004; Maney et al., 2006; Lynch and Wilczynski, 2008). Such a role of sex steroid hormones in vertebrates results from activity within a "social behavioral network" that includes sexual motivational brain areas such as the medial preoptic area of the hypothalamus and the medial extended amygdala (Newman, 1999; Goodson, 2005). However, recent evidence indicates that sex steroid hormones may directly impact sensory processing in a variety of vertebrate species, including humans, monkeys, fish, and frogs (Sisneros et al., 2004; Lynch and Wilczynski, 2006, 2008; Maney et al., 2006). Although the site of action of such hormone-driven alterations in sensory processing may vary across species, our work indicates that the impact of steroid hormones may be exerted directly on primary sensory areas, through both rapid modulation of neuronal responsiveness and long-term gene expression-dependent mechanisms.

To the best of our knowledge, our findings provide the first description of an acute modulation of neural physiology by brain-generated E2 during the processing of sensory information in an awake vertebrate species.

\section{References}

Abrahám IM, Herbison AE (2005) Major sex differences in non-genomic estrogen actions on intracellular signaling in mouse brain in vivo. Neuroscience 131:945-951.

Aronica SM, Kraus WL, Katzenellenbogen BS (1994) Estrogen action via the cAMP signaling pathway: stimulation of adenylate cyclase and cAMPregulated gene transcription. Proc Natl Acad Sci U S A 91:8517-8521.

Balthazart J, Foidart A, Wilson EM, Ball GF (1992) Immunocytochemical localization of androgen receptors in the male songbird and quail brain. J Comp Neurol 317:407-420.

Balthazart J, Baillien M, Charlier TD, Cornil CA, Ball GF (2003) Multiple mechanisms control brain aromatase activity at the genomic and nongenomic level. J Steroid Biochem Mol Biol 86:367-379.

Bernard DJ, Bentley GE, Balthazart J, Turek FW, Ball GF (1999) Androgen receptor, estrogen receptor alpha, and estrogen receptor beta show distinct patterns of expression in forebrain song control nuclei of European starlings. Endocrinology 140:4633-4643.

Bi R, Broutman G, Foy MR, Thompson RF, Baudry M (2000) The tyrosine kinase and mitogen-activated protein kinase pathways mediate multiple effects of estrogen in hippocampus. Proc Natl Acad Sci USA 97:3602-3607.

Bolhuis JJ, Gahr M (2006) Neural mechanisms of birdsong memory. Nat Rev Neurosci 7:347-357.

Cheng HY, Clayton DF (2004) Activation and habituation of extracellular signal-regulated kinase phosphorylation in zebra finch auditory forebrain during song presentation. J Neurosci 24:7503-7513.

Chesnoy-Marchais D (2003) Potentiation of glycine responses by dideoxyforskolin and tamoxifen in rat spinal neurons. Eur J Neurosci 17:681-691.

Chesnoy-Marchais D (2005) The estrogen receptor modulator tamoxifen enhances spontaneous glycinergic synaptic inhibition of hypoglossal motoneurons. Endocrinology 146:4302-4311.

Chew SJ, Mello C, Nottebohm F, Jarvis E, Vicario DS (1995) Decrements in auditory responses to a repeated conspecific song are long-lasting and require two periods of protein synthesis in the songbird forebrain. Proc Natl Acad Sci U S A 92:3406-3410.

Chew SJ, Vicario DS, Nottebohm F (1996) A large-capacity memory system that recognizes the calls and songs of individual birds. Proc Natl Acad Sci U S A 93:1950-1955.

Coleman JR, Campbell D, Cooper WA, Welsh MG, Moyer J (1994) Auditory brainstem responses after ovariectomy and estrogen replacement in rat. Hear Res 80:209-215. 
Cornil CA, Ball GF, Balthazart J (2006) Functional significance of the rapid regulation of brain estrogen action: where do the estrogens come from? Brain Res 1126:2-26.

Craft RM, Mogil JS, Aloisi AM (2004) Sex differences in pain and analgesia: the role of gonadal hormones. Eur J Pain 8:397-411.

Davis MJ, Ahroon WA (1982) Fluctuations in susceptibility to noiseinduced temporary threshold shift as influenced by the menstrual cycle. J Aud Res 22:173-187.

Dick GM, Sanders KM (2001) (Xeno)estrogen sensitivity of smooth muscle BK channels conferred by the regulatory betal subunit: a study of betal knockout mice. J Biol Chem 276:44835-44840.

Duncan RK (2005) Tamoxifen alters gating of the BK alpha subunit and mediates enhanced interactions with the avian beta subunit. Biochem Pharmacol 70:47-58.

Fillit H, Weinreb H, Cholst I, Luine V, McEwen B, Amador R, Zabriskie J (1986) Observations in a preliminary open trial of estradiol therapy for senile dementia-Alzheimer's type. Psychoneuroendocrinology 11:337-345.

Foy MR (2001) 17beta-estradiol: effect on CA1 hippocampal synaptic plasticity. Neurobiol Learn Mem 76:239-252.

Foy MR, Xu J, Xie X, Brinton RD, Thompson RF, Berger TW (1999) 17betaestradiol enhances NMDA receptor-mediated EPSPs and long-term potentiation. J Neurophysiol 81:925-929.

Fusani L, Hutchison JB, Gahr M (2001) Testosterone regulates the activity and expression of aromatase in the canary neostriatum. J Neurobiol 49:1-8.

Gentner TQ (2004) Neural systems for individual song recognition in adult birds. Ann N Y Acad Sci 1016:282-302.

Golub MS, Germann SL, Hogrefe CE (2004) Endocrine disruption and cognitive function in adolescent female rhesus monkeys. Neurotoxicol Teratol 26:799-809.

Goodson JL (2005) The vertebrate social behavior network: evolutionary themes and variations. Horm Behav 48:11-22.

Gu Q, Moss RL (1996) $17 \beta$-Estradiol potentiates kainate-induced currents via activation of the cAMP cascade. J Neurosci 16:3620-3629.

Güngör N, Böke B, Belgin E, Tunçbilek E (2000) High frequency hearing loss in Ullrich-Turner syndrome. Eur J Pediatr 159:740-744.

Herbison AE (1997) Estrogen regulation of GABA transmission in rat preoptic area. Brain Res Bull 44:321-326.

Herbison AE, Fénelon VS (1995) Estrogen regulation of $\mathrm{GABA}_{\mathrm{A}}$ receptor subunit mRNA expression in preoptic area and bed nucleus of the stria terminalis of female rat brain. J Neurosci 15:2328-2337.

Hu R, Cai WQ, Wu XG, Yang Z (2007) Astrocyte-derived estrogen enhances synapse formation and synaptic transmission between cultured neonatal rat cortical neurons. Neuroscience 144:1229-1240.

Hultcrantz M, Sylvén L (1997) Turner's syndrome and hearing disorders in women aged 16-34. Hear Res 103:69-74.

Hultcrantz M, Sylvén L, Borg E (1994) Ear and hearing problems in 44 middle-aged women with Turner's syndrome. Hear Res 76:127-132.

Jerger J, Hall J (1980) Effects of age and sex on auditory brainstem response. Arch Otolaryngol 106:387-391.

Jover-Mengual T, Zukin RS, Etgen AM (2007) MAPK signaling is critical to estradiol protection of CA1 neurons in global ischemia. Endocrinology 148:1131-1143.

Kelly MJ, Qiu J, Rønnekleiv OK (2003) Estrogen modulation of G-proteincoupled receptor activation of potassium channels in the central nervous system. Ann N Y Acad Sci 1007:6-16.

Kow LM, Devidze N, Pataky S, Shibuya I, Pfaff DW (2006) Acute estradiol application increases inward and decreases outward whole-cell currents of neurons in rat hypothalamic ventromedial nucleus. Brain Res 1116:1-11.

Kumar A, Foster TC (2002) 17beta-estradiol benzoate decreases the AHP amplitude in CA1 pyramidal neurons. J Neurophysiol 88:621-626.

Lin F, Xin Y, Wang J, Ma L, Liu J, Liu C, Long L, Wang F, Jin Y, Zhou J, Chen $\mathrm{J}$ (2007) Puerarin facilitates $\mathrm{Ca}^{2+}$-induced $\mathrm{Ca}^{2+}$ release triggered by $\mathrm{KCl}$-depolarization in primary cultured rat hippocampal neurons. Eur J Pharmacol 570:43-49.

London SE, Clayton DF (2008) Functional identification of sensory mechanisms required for developmental song learning. Nat Neurosci 11:579-586.

Lynch KS, Wilczynski W (2006) Social regulation of plasma estradiol concentration in a female anuran. Horm Behav 50:101-106.
Lynch KS, Wilczynski W (2008) Reproductive hormones modify reception of species-typical communication signals in a female anuran. Brain Behav Evol 71:143-150.

MacGregor JI, Jordan VC (1998) Basic guide to the mechanisms of antiestrogen action. Pharmacol Rev 50:151-196.

Maggi A, Perez J (1984) Progesterone and estrogens in rat brain: modulation of GABA (gamma-aminobutyric acid) receptor activity. Eur J Pharmacol 103:165-168.

Maney DL, Cho E, Goode CT (2006) Estrogen-dependent selectivity of genomic responses to birdsong. Eur J Neurosci 23:1523-1529.

Mannella P, Brinton RD (2006) Estrogen receptor protein interaction with phosphatidylinositol 3-kinase leads to activation of phosphorylated Akt and extracellular signal-regulated kinase $1 / 2$ in the same population of cortical neurons: a unified mechanism of estrogen action. J Neurosci 26:9439-9447.

Marino M, Galluzzo P, Ascenzi P (2006) Estrogen signaling multiple pathways to impact gene transcription. Curr Genomics 7:497-508.

McCarthy MM (2008) Estradiol and the developing brain. Physiol Rev 88:91-124.

McEwen B (2002) Estrogen actions throughout the brain. Recent Prog Horm Res 57:357-384

McEwen BS, Alves SE (1999) Estrogen actions in the central nervous system. Endocr Rev 20:279-307.

Mello CV, Pinaud R (2006) Immediate early gene regulation in the auditory system. In: Immediate early genes in sensory processing, cognitive performance and neurological disorders (Pinaud R, Tremere LA, eds), pp 3556. New York: Springer.

Mello CV, Vicario DS, Clayton DF (1992) Song presentation induces gene expression in the songbird forebrain. Proc Natl Acad Sci U SA 89:6818-6822.

Mello C, Nottebohm F, Clayton D (1995) Repeated exposure to one song leads to a rapid and persistent decline in an immediate early gene's response to that song in zebra finch telencephalon. J Neurosci 15:6919-6925.

Mello CV, Vates GE, Okuhata S, Nottebohm F (1998) Descending auditory pathways in the adult male zebra finch (Taeniopygia guttata). J Comp Neurol 395:137-160.

Mello CV, Velho TA, Pinaud R (2004) Song-induced gene expression: a window on song auditory processing and perception. Ann N Y Acad Sci 1016:263-281.

Metzdorf R, Gahr M, Fusani L (1999) Distribution of aromatase, estrogen receptor, and androgen receptor $\mathrm{mRNA}$ in the forebrain of songbirds and nonsongbirds. J Comp Neurol 407:115-129.

Newman SW (1999) The medial extended amygdala in male reproductive behavior. A node in the mammalian social behavior network. Ann N Y Acad Sci 877:242-257.

Nishimura I, Ui-Tei K, Saigo K, Ishii H, Sakuma Y, Kato M (2008) 17betaestradiol at physiological concentrations augments $\mathrm{Ca}^{2+}$-activated $\mathrm{K}^{+}$ currents via estrogen receptor beta in the gonadotropin-releasing hormone neuronal cell line GT1-7. Endocrinology 149:774-782.

Nowicki S, Searcy WA (2004) Song function and the evolution of female preferences: why birds sing, why brains matter. Ann N Y Acad Sci 1016:704-723.

Ostlund H, Keller E, Hurd YL (2003) Estrogen receptor gene expression in relation to neuropsychiatric disorders. Ann N Y Acad Sci 1007:54-63.

Pinaud R, Terleph TA (2008) A songbird forebrain area potentially involved in auditory discrimination and memory formation. J Biosci 33:145-155.

Pinaud R, Velho TA, Jeong JK, Tremere LA, Leão RM, von Gersdorff H, Mello CV (2004) GABAergic neurons participate in the brain's response to birdsong auditory stimulation. Eur J Neurosci 20:1318-1330.

Pinaud R, Fortes AF, Lovell P, Mello CV (2006) Calbindin-positive neurons reveal a sexual dimorphism within the songbird analogue of the mammalian auditory cortex. J Neurobiol 66:182-195.

Pinaud R, Osorio C, Alzate O, Jarvis ED (2008a) Profiling of experienceregulated proteins in the songbird auditory forebrain using quantitative proteomics. Eur J Neurosci 27:1409-1422.

Pinaud R, Mello CV, Velho TA, Wynne RD, Tremere LA (2008b) Detection of two mRNA species at single-cell resolution by double-fluorescence in situ hybridization. Nat Protoc 3:1370-1379.

Pinaud R, Terleph TA, Tremere LA, Phan ML, Dagostin AA, Leão RM, Mello CV, Vicario DS (2008c) Inhibitory network interactions shape the audi- 
tory processing of natural communication signals in the songbird auditory forebrain. J Neurophysiol 100:441-455.

Remage-Healey L, Maidment NT, Schlinger BA (2008) Forebrain steroid levels fluctuate rapidly during social interactions. Nat Neurosci 11:1327-1334.

Romanò N, Lee K, Abrahám IM, Jasoni CL, Herbison AE (2008) Nonclassical estrogen modulation of presynaptic GABA terminals modulates calcium dynamics in gonadotropin-releasing hormone neurons. Endocrinology 149:5335-5344.

Rudick CN, Woolley CS (2003) Selective estrogen receptor modulators regulate phasic activation of hippocampal CAl pyramidal cells by estrogen. Endocrinology 144:179-187.

Rudick CN, Gibbs RB, Woolley CS (2003) A role for the basal forebrain cholinergic system in estrogen-induced disinhibition of hippocampal pyramidal cells. J Neurosci 23:4479-4490.

Safe S, Kim K (2008) Non-classical genomic estrogen receptor (ER)/specificity protein and ER/activating protein-1 signaling pathways. J Mol Endocrinol 41:263-275.

Saldanha CJ, Coomaralingam L (2005) Overlap and co-expression of estrogen synthetic and responsive neurons in the songbird brain: a doublelabel immunocytochemical study. Gen Comp Endocrinol 141:66-75.

Saldanha CJ, Tuerk MJ, Kim YH, Fernandes AO, Arnold AP, Schlinger BA (2000) Distribution and regulation of telencephalic aromatase expression in the zebra finch revealed with a specific antibody. J Comp Neurol 423:619-630.

Schlinger BA, Arnold AP (1991) Brain is the major site of estrogen synthesis in a male songbird. Proc Natl Acad Sci U S A 88:4191-4194.

Schlinger BA, Arnold AP (1992) Circulating estrogens in a male songbird originate in the brain. Proc Natl Acad Sci U S A 89:7650-7653.

Schumacher M, Coirini H, McEwen BS (1989) Regulation of high-affinity GABAA receptors in the dorsal hippocampus by estradiol and progesterone. Brain Res 487:178-183.

Schwarz JM, Liang SL, Thompson SM, McCarthy MM (2008) Estradiol induces hypothalamic dendritic spines by enhancing glutamate release: a mechanism for organizational sex differences. Neuron 58:584-598.

Shen P, Schlinger BA, Campagnoni AT, Arnold AP (1995) An atlas of aromatase mRNA expression in the zebra finch brain. J Comp Neurol 360:172-184.

Singh M, Sétáló G Jr, Guan X, Warren M, Toran-Allerand CD (1999)
Estrogen-induced activation of mitogen-activated protein kinase in cerebral cortical explants: convergence of estrogen and neurotrophin signaling pathways. J Neurosci 19:1179-1188.

Sisneros JA, Forlano PM, Deitcher DL, Bass AH (2004) Steroid-dependent auditory plasticity leads to adaptive coupling of sender and receiver. Science 305:404-407.

Stripling R, Kruse AA, Clayton DF (2001) Development of song responses in the zebra finch caudomedial neostriatum: role of genomic and electrophysiological activities. J Neurobiol 48:163-180.

Sweatt JD (2001) The neuronal MAP kinase cascade: a biochemical signal integration system subserving synaptic plasticity and memory. J Neurochem 76:1-10.

Thomas GM, Huganir RL (2004) MAPK cascade signalling and synaptic plasticity. Nat Rev Neurosci 5:173-183.

Vates GE, Broome BM, Mello CV, Nottebohm F (1996) Auditory pathways of caudal telencephalon and their relation to the song system of adult male zebra finches. J Comp Neurol 366:613-642.

Velho TA, Pinaud R, Rodrigues PV, Mello CV (2005) Co-induction of activity-dependent genes in songbirds. Eur J Neurosci 22:1667-1678.

Wade J, Schlinger BA, Hodges L, Arnold AP (1994) Fadrozole: a potent and specific inhibitor of aromatase in the zebra finch brain. Gen Comp Endocrinol 94:53-61.

Walpurger V, Pietrowsky R, Kirschbaum C, Wolf OT (2004) Effects of the menstrual cycle on auditory event-related potentials. Horm Behav 46:600-606.

Wong M, Moss RL (1992) Long-term and short-term electrophysiological effects of estrogen on the synaptic properties of hippocampal CA1 neurons. J Neurosci 12:3217-3225.

Woolley CS (2007) Acute effects of estrogen on neuronal physiology. Annu Rev Pharmacol Toxicol 47:657-680.

Zhang H, Xie M, Schools GP, Feustel PF, Wang W, Lei T, Kimelberg HK, Zhou M (2009) Tamoxifen mediated estrogen receptor activation protects against early impairment of hippocampal neuron excitability in an oxygen/glucose deprivation brain slice ischemia model. Brain Res 1247:196-211.

Znamensky V, Akama KT, McEwen BS, Milner TA (2003) Estrogen levels regulate the subcellular distribution of phosphorylated Akt in hippocampal CA1 dendrites. J Neurosci 23:2340-2347. 